Review

\title{
Textile-Based Electronic Components for Energy Applications: Principles, Problems, and Perspective
}

\author{
Vishakha Kaushik, Jaehong Lee, Juree Hong, Seulah Lee, Sanggeun Lee, Jungmok Seo, \\ Chandreswar Mahata and Taeyoon Lee *
}

Nanobio Device Laboratory, School of Electrical and Electronic Engineering, Yonsei University, 50 Yonsei-ro, Seodaemun-Gu, Seoul 120-749, Korea; E-Mails: vishakhakaushik@gmail.com (V.K.); sotage2@gmail.com (J.L.); juree@yonsei.ac.kr (J.H.); esa0605@yonsei.ac.kr (S.L.); sang0927@yonsei.ac.kr (S.L.); jungmok.seo@gmail.com (J.S.); chandreswar@gmail.com (C.M.)

* Author to whom correspondence should be addressed; E-Mail: taeyoon.lee@yonsei.ac.kr; Tel.: +82-2-2123-5767; Fax: +82-2-2123-2879.

Academic Editor: Jiye Fang

Received: 5 August 2015 / Accepted: 26 August 2015 / Published: 7 September 2015

\begin{abstract}
Textile-based electronic components have gained interest in the fields of science and technology. Recent developments in nanotechnology have enabled the integration of electronic components into textiles while retaining desirable characteristics such as flexibility, strength, and conductivity. Various materials were investigated in detail to obtain current conductive textile technology, and the integration of electronic components into these textiles shows great promise for common everyday applications. The harvest and storage of energy in textile electronics is a challenge that requires further attention in order to enable complete adoption of this technology in practical implementations. This review focuses on the various conductive textiles, their methods of preparation, and textile-based electronic components. We also focus on fabrication and the function of textile-based energy harvesting and storage devices, discuss their fundamental limitations, and suggest new areas of study.
\end{abstract}

Keywords: wearable electronics; textile electronics; conductive fabric; textile sensors; energy harvesting and storage 


\section{Introduction}

Electronic devices have the ability to address basic needs [1-6]. When electronic devices were first being developed, scientists imagined great leaps forward such as the development of artificial intelligence, and realized the innovation of the Bell telephone in 1876 [7]. A complex number calculator was later developed by the Bell laboratory in 1939 [8]. Seven years after this valuable development, the first fully-functional digital computer, known as ENIAC, came into existence [9]. Although ENIAC was the fastest machine at that time, it was difficult to physically transport due to size $\left(2.4 \times 0.9 \times 30 \mathrm{~m}^{3}\right)$ and power requirements $(150 \mathrm{~kW})$. Thus, the primary goals of researchers at this time were to decrease the size and power consumption of electronic devices, which they did with the miniaturization of electronic devices and developed the first personal computer, Kenbak-1, and the first laptop computer, Epson HX-20 [10-12]. The increasing pace of technological developments since the late 20th century has resulted in exploration of mobile and wearable devices $[13,14]$. Early stage wearable computers were composed of backpack systems with uncomfortable wiring networks. Currently, researchers aim to develop flexible wearable devices that integrate seamlessly into regular clothing such as Google glass, the Apple watch, and electronic skins [15-18]. An illustration of the history of these electronic components from Bell's telephone to smart wearable devices is presented in Figure 1 [7-19]. Recent market demand has focused on small electronic components for smart wearable device applications, leading to research and products featuring technology that can directly integrate electronic components into textiles or fabrics for a variety of applications including sensors, medical devices, safety instruments, and planar waveguides [4,20-31].

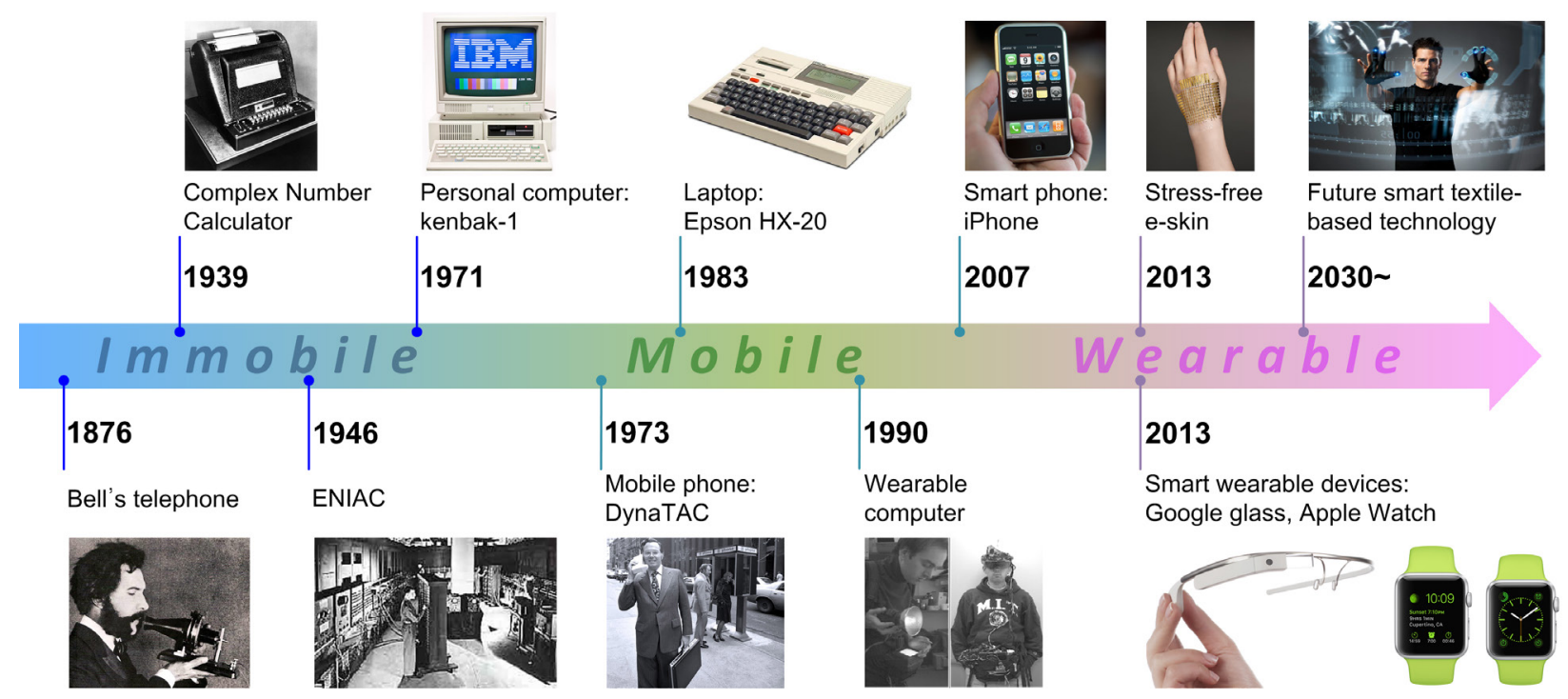

Figure 1. A chronological illustration presenting the journey of electronic components from immobile to mobile, and finally to wearable textile-based electronics.

Textiles have been used by mankind since prehistoric times, and they are essential to daily life. Fashion dictates that the textiles must look attractive and fit comfortably. Traditional textiles are composed of natural or synthetic fibers and filaments. Recent advances in electronics have led to the development of a new generation known as electronic textiles (E-textiles) or smart textiles. E-textiles consist of fabric that provides advanced functions in the form of electronic features or 
interconnection [32,33]. E-textiles can be categorized into two types: classical, where the electronic components are embedded into garments and integrated, where the electronic components are directly integrated into textile substrates. E-textiles have attracted attention in technical and socioeconomic fields because of their ability to sense and respond to environmental stimuli [33,34]. Due to this ability, they are ideal components for smart wearable electronics, and represent a new branch of flexible multifunctional fabric electronics. Many research groups have explored the integration of flexible devices such as solar cells, field-effect transistors (FETs), light emitting diodes (OLEDs), and photovoltaic devices into textiles; however, these components cannot operate without sufficient electrical energy, making the development of energy harvesting and storage devices essential [35-46].

This paper reviews the development of various key components that are required for E-textiles. The most fundamental element is the conductive textile, which is required for interconnection to transfer power and data. Energy harvesting and storing applications are necessary for powering the electrical components such as transistors, LEDs, and sensors for their utilization in various functional E-textiles. A systematic view is suggested and elucidated with examples.

\section{Conductive Textile: Materials and Fabrication}

It is ideal for electronic interconnects to be realized on fibers or fabrics for the fabrication of textile-based wearable devices. The development of highly-conductive textiles for interconnection is crucial to minimize energy loss. Three types of materials have been explored for the fabrication of high-conductivity textiles: polymer-based, carbon-based, and metallic materials. In this section, the features of conductive textiles consisting of organic and inorganic materials will be discussed.

\subsection{Polymer-Based Conductive Textiles}

Conductive polymers have attracted significant scientific interest for their interesting and unique electrical, optical, and mechanical properties [47-49]. They have been explored in a number of applications such as chemical and biological sensors, drug delivery, corrosion protection, nanoelectronic devices, biomedicine, microwave absorption, and electrocatalysis [50-59]. Shirakawa et al. were the first to demonstrate conductivity in polymers via doping, showing that exposure of polyacetylene (PA) polymer to iodine vapor increases conductivity by up to seven orders of magnitude [60]. The enhanced conductivity of PA is attributed to redox reactions (charge transfer complexes) between the PA and iodine vapor. The search for highly conductive polymers has resulted in the expansion of this area, and a number of conductive polymers have been used in the last 35 years. Various applications such as protective clothing, sportswear, health monitoring, actuators, and sensors for wearable E-textiles have now been explored via these conductive polymer fabrics [61-65].

Conjugated polymer polypyrrole (PPy) has received much attention due to its high conductivity paired with chemical and environmental stability [66,67]. PPy also has the advantage of being easy to synthesize at large areas with different porosities at room temperature. Conductive polymer textiles can be fabricated via polymerization, wet spinning, or dip coating processes [68-70]. In situ polymerization or chemical oxidation polymerization are commonly used [71,72]. The experimental steps used to fabricate conductive PPy via in-situ chemical polymerization are illustrated in Figure 2a. Highly-conductive PPy nanofibers with diameters between 60 and $100 \mathrm{~nm}$ that are synthesized in 
p-hydroxyazobenzene sulfonic acid act as a functional dopant. PPy is deposited when the fabric and polymer solutions come into contact due to the liquid-solid interface interaction. This is considered a physical adsorption followed by a polymerization process, and results in a layer of conducting polymer with a smooth surface over the fibers. PPy can also be deposited onto other complex structures. Figure $2 b$ shows the scanning electron microscope (SEM) image of a conductive fiber composed of carbon nanotube bundles coated with PPy [73]; however, brittleness and rigidity are two potential drawbacks to using PPy.
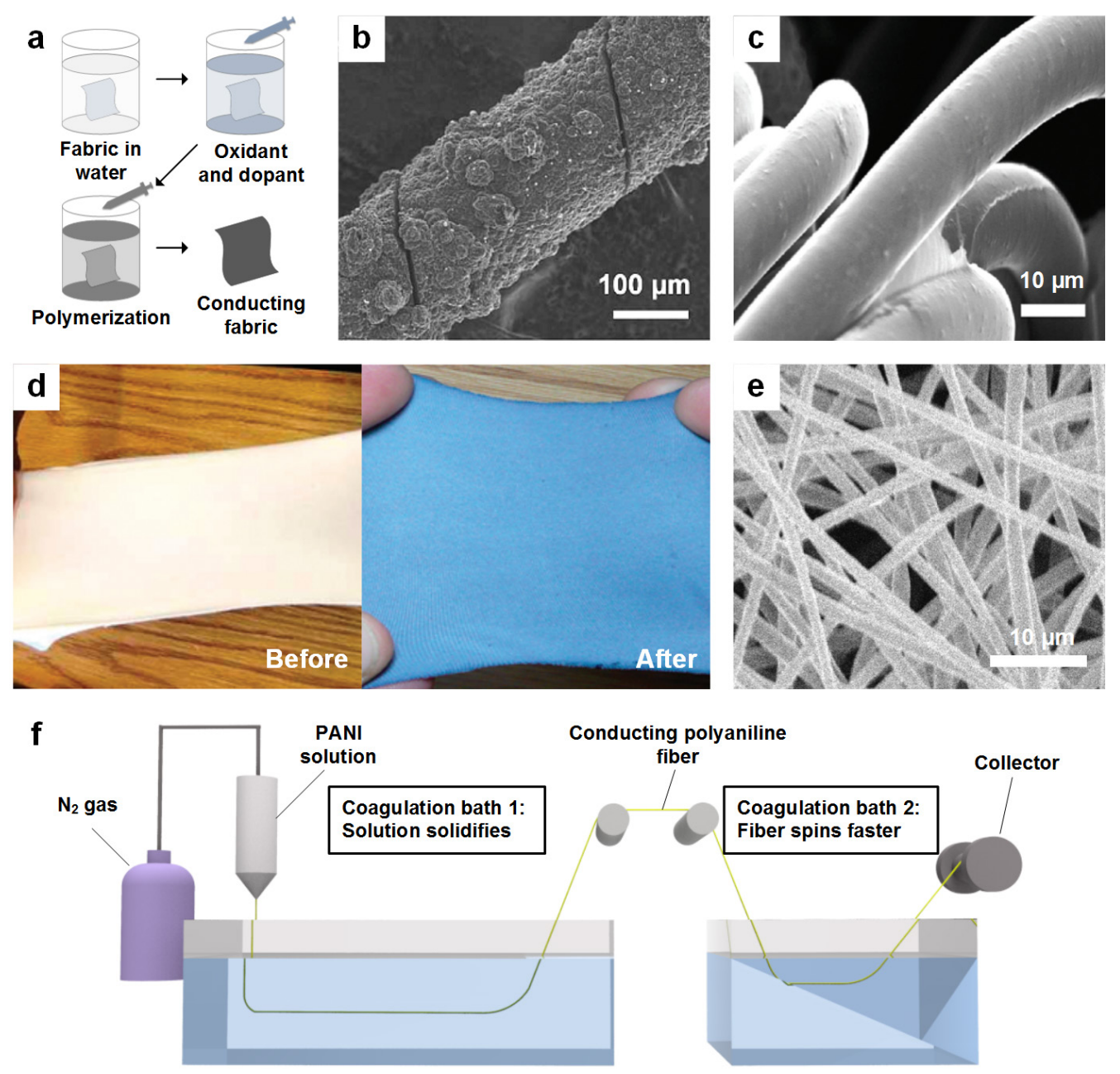

Conducting polyaniline

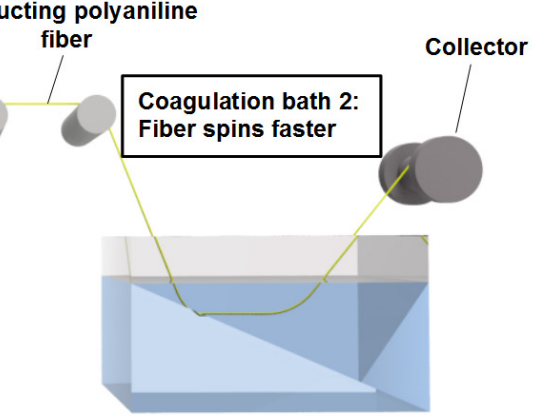

Figure 2. (a) Schematic illustration of the in situ chemical polymerization for conducting polymer-coated fabric; (b) SEM image of a conductive fiber composed of carbon nanotube bundles coated with polypyrrole; (c) SEM micrograph of stretchable spandex fabric after a dip coating process with polystyrene sulfonate-doped poly-(3,4-ethylenedioxythiophene) (PEDOT:PSS); (d) Optical image of stretchable fabric before and after dip coating with PEDOT:PSS; (e) Surface morphology of polyaniline (PANI): polyethylene oxide (PEO) electrospun fiber; (f) Wet fiber spinning technique process. Reproduced from [68,73,74] with the permission by Royal Society of Chemistry, Copyright 2015, and by ACS Publications, Copyright 2010, 2012. 
Another interesting conductive polymer is a polythiophene derivative, poly-(3,4-ethylenedioxythiophene) (PEDOT), which shows high electrochemical stability in oxidized form due to its planar structure and delocalized $\pi$ electrons [75]. Its unique structure contains dioxyalkylene bridging groups at positions 3 and 4 of its heterocycle ring, making it the most valuable among all conducting polymers. Thus, it shows high conductivity and good electrical, thermal, and chemical stability when compared to PPy. Although PEDOT itself is a conductive polymer, it has low solubility, which limits usage. Generally, polystyrene sulfonate (PSS)-doped PEDOT (PEDOT:PSS) is used to obtain a stable dispersion in a water solvent. PEDOT:PSS has been used extensively in the last few years as a conducting polymer [76]. The simplest technique for coating is dip coating, where the fabric is simply dipped into the conductive solution, resulting in a conductive polymer fabric. Ding et al. have reported the preparation of PEDOT:PSS conductive fabrics using the dip coating process [68]. Figure $2 \mathrm{c}$ shows the surface morphology of a spandex fabric after soaking in a commercially-available PEDOT:PSS dispersion. It is clear from the Figure 2c that the surface of the fabric is smooth and uniform after conductive coating. The conductivity of the single soaked fabric was reported to be $0.1 \mathrm{~S} / \mathrm{cm}$, reaching up to $2 \mathrm{~S} / \mathrm{cm}$ after multiple soaking steps. The optical image of the PEDOT:PSS-soaked textile is shown in Figure $2 \mathrm{~d}$. Thus, conductive fabrics can be produced in a simple manner.

Polyaniline (PANI), known as aniline black, has also been studied as a conductive polymer. PANI revolutionized polymer chemistry due to its many advantages including stability, cost effectiveness, and switching characteristics between conductive and resistive states. Its electrical conductivity is due to the partial oxidation or reduction process and can be tuned to achieve the required conductivity for a given application. It is fabricated via a chemical oxidative polymerization process of aniline, which is a multistep and slightly complex process. Figure 2e shows the surface morphology of electrospun PANI fibers that exhibit high electrical conductivity between 70 and $150 \mathrm{~S} / \mathrm{cm}$ [74]. However, a more simplified, single-step fabrication method is reported by Pomfret et al. where polyaniline fibers are fabricated using a wet spinning process [77]. The resulting fibers exhibited high conductivity ( $\sim 1000 \mathrm{~S} / \mathrm{cm}$ for bulk material) and good mechanical strength (young modulus $\sim 2 \mathrm{GPa}$ ). Figure $2 \mathrm{f}$ shows the schematic design of the wet spinning process utilized for the production of conductive polyaniline polymer. A mixture of organic solvents and the emeraldine base form of polyaniline is used to make a spinning solution, which then enters the first coagulation bath where it solidifies and forms fibers. In the second coagulation bath, the fibers spin rapidly, resulting in stretching. The stretched fibers are then doped with an acid suitable for the preparation of conducting fibers, as shown in Figure 2f. As discussed earlier, conductive polymers are considered useful in wearable textiles; however, the conductivity values should be modified for their optimization in the production of smart wearable electronics. A comparison of the properties of these conductive fibers is given in Table 1. 
Table 1. Summary of materials and their electric properties.

\begin{tabular}{|c|c|c|c|c|c|c|c|}
\hline $\begin{array}{c}\text { Structure of } \\
\text { conductive } \\
\text { textile } \\
\end{array}$ & $\begin{array}{l}\text { Material use to prepare } \\
\text { or to coat on fibers }\end{array}$ & Merits of Conductive textiles & $\begin{array}{l}\text { Technique used to fabricate } \\
\text { conductive textile }\end{array}$ & Advantages of growth technique & $\begin{array}{c}\text { Disadvantages of growth } \\
\text { technique }\end{array}$ & $\begin{array}{l}\text { Electrical } \\
\text { property }\end{array}$ & Ref. \\
\hline \multirow{3}{*}{ Polymer-based } & Polypyrrole & $\begin{array}{l}\text { Chemical and environment } \\
\text { stable }\end{array}$ & Functional dopant induced process & $\begin{array}{l}\text { Novel \& Easy process, } \\
\text { High Yield easily deposit } \\
\text { on fabric surface }\end{array}$ & $\begin{array}{l}\text { Need to optimize dopant } \\
\text { concentration for better } \\
\text { conductivity results }\end{array}$ & $120-130 \mathrm{~S} / \mathrm{cm}$ & [78] \\
\hline & Polyaniline & Cost effective, stable & Wet Spinning & $\begin{array}{l}\text { Produced fibers show high } \\
\text { electronic and mechanical } \\
\text { strength, fabricated thick fibers }\end{array}$ & Need to combine Individual fibers & $140-750 \mathrm{~S} / \mathrm{cm}$ & [79-81] \\
\hline & PEDOT:PSS & $\begin{array}{l}\text { Highly conductive good } \\
\text { thermal and chemical stability }\end{array}$ & Dip Coating & Simple process & Coating is slow, tide lines can forms & $0.4-2.0 \mathrm{~S} / \mathrm{cm}$ & {$[68,82]$} \\
\hline \multirow{2}{*}{ Carbon-based } & Graphene & $\begin{array}{l}\text { Highly conductive \& stable, } \\
\text { high strength }\end{array}$ & $\begin{array}{l}\text { Electrostatic self-assembly with } \\
\text { BSA followed by chemical reduction }\end{array}$ & $\begin{array}{l}\text { Easy to attach graphene oxide } \\
\text { films to textiles }\end{array}$ & $\begin{array}{l}\text { Multistep process, wrinkles } \\
\text { observed on surface of samples }\end{array}$ & $10-20 \mathrm{~S} / \mathrm{cm}$ & {$[83,84]$} \\
\hline & Carbon nanotubes & $\begin{array}{l}\text { Conductive, high mechanical } \\
\text { strength }\end{array}$ & Wet spinning & $\begin{array}{l}\text { Continuous long length }(\mathrm{cm}) \\
\text { CNT yarns }\end{array}$ & Slow processing & $125-3000 \mathrm{~S} / \mathrm{cm}$ & [85-87] \\
\hline \multirow{2}{*}{ Metal-based } & Al-coated conductive paper & Stable, conductive, stretchable & Chemical solution process & $\begin{array}{l}\text { Low cost, Vacuum not required, } \\
\text { Direct deposition of } \mathrm{Al} \text { on fibers }\end{array}$ & $\begin{array}{l}\text { Need a suitable catalyst for } \\
\text { decomposition process }\end{array}$ & $19 \mathrm{~m} \Omega / \square$ & [88] \\
\hline & AgNP/Ag nanowires & Conductive & Wet spinning & Simple, highly conductive material & $\begin{array}{l}\text { Need optimization of suitable } \\
\text { solvents and coagulation liquids }\end{array}$ & $2200-5400 \mathrm{~S} / \mathrm{cm}$ & {$[89,90]$} \\
\hline
\end{tabular}




\subsection{Carbon-Based Conductive Textile}

Carbon-based materials including carbon nanotubes (CNTs), carbon fibers, carbon nanoparticles, and graphene present extraordinary properties such as high mechanical strength, light weight, environmental stability, and superior thermal and electrical conductivity [91-98]. These intriguing properties make carbon-based materials important candidates in wearable electronic textiles. Among all carbon allotropes, the most widely explored are CNTs and graphene. While carbon fibers have been explored in the textile industry for a long time, CNTs are increasingly chosen over commercial carbon fibers because of their lower density, and higher tensile and compressive strength [99-101]. CNT can be coated on various fibers such as cellulose or polyester yarns via a simple and cost effective dipping and drying method, as shown in Figure 3a [87]. Here, cotton fibers are simply dipped into a single-walled carbon nanotube (SWCNT) solution, resulting in a black conductive fabric. Figure $3 b$ shows the surface morphology of the SWCNT-coated cotton fibers. The as-prepared CNT-cotton yarns show high electrical conductivity $(125 \mathrm{~S} / \mathrm{cm})$ with outstanding stretchability and flexibility. The coating of CNTs results in conductivity of fibers and a CNT-cotton thread can emit the light of an LED, as shown in Figure 3c [102].

CNT fibers without any supportive fiber can be made using wet or dry spinning methods. Zhang et al. reported a wet spinning method for the production of long CNTs; a schematic of their wet spinning process is shown in Figure 3d [103]. The electrical conductivity of CNT fibers was enhanced up to $\sim 6.7 \times 10^{4} \mathrm{~S} / \mathrm{cm}$ by iodine-doping [104]. The enhancement in the conductivity of CNT fibers via doping is shown in Figure 3e [104]. Jiang et al. have fabricated CNT yarns using a super-aligned array of CNTs [105]. The way to produce continuous CNT yarns $30 \mathrm{~cm}$ in length from a CNT array is similar to drawing a thread from a silkworm cocoon. Figure $3 \mathrm{f}$ shows an optical image of the yarn pulled from a CNT array [105]. The authors have constructed a light bulb filament using these CNT yarns and observed that their strength and conductivity is enhanced by heating at high temperatures. The CNT-yarn-based filament emits incandescent light for $3 \mathrm{~h}$, and after this time span the conductivity of the filament increases by up to $13 \%$, while the tensile strength of the CNT yarn increased from $1 \mathrm{mN}$ to $6.4 \mathrm{mN}$. Thus, these CNT yarns can be woven into fabrics [105]. However, this process has some disadvantages in terms of slow processing and limited to scaling for thick or multistrand forms. Other issues include high junction resistance.

Graphene oxide (GO) has also been widely studied for conductive fibers. Yun et al. presented an electrostatic method for fabricating textiles that are wrapped with reduced graphene oxide (RGO), which makes them conductive and stable (Figure 3g) [83]. Nylon-6 yarns were functionalized with bovine serum albumin molecules to obtain positively-charged surfaces. GO sheets were then electrostatically assembled over the fibers via a simple immersing and shaking process in a GO solution [83]. Finally, the GO are chemically reduced to RGO. They have also demonstrated the lightning of an LED using the synthesized conductive fibers, a process that works well even after folding, as shown in Figure 3h [83]. Freestanding RGO fibers can also be synthesized using wet or dry spinning methods. $\mathrm{Xu}$ et al. have reported porous graphene oxide with good electrical conductivity $\left(\sim 4.9 \times 10^{3} \mathrm{~S} / \mathrm{m}\right)$ and high specific surface area $\left(884 \mathrm{~m}^{2} \cdot \mathrm{g}^{-1}\right)$ [106]. This graphene-based hybrid structure presents great potential in fiber-based electrochemical super-capacitors [84]. The above described properties of carbon-based materials open a new path in electronic textiles for wearable 
electronics. However, further investigation is needed to look into the possible side effects of wearable electronics, such as toxicity with skin contact and stability in air.
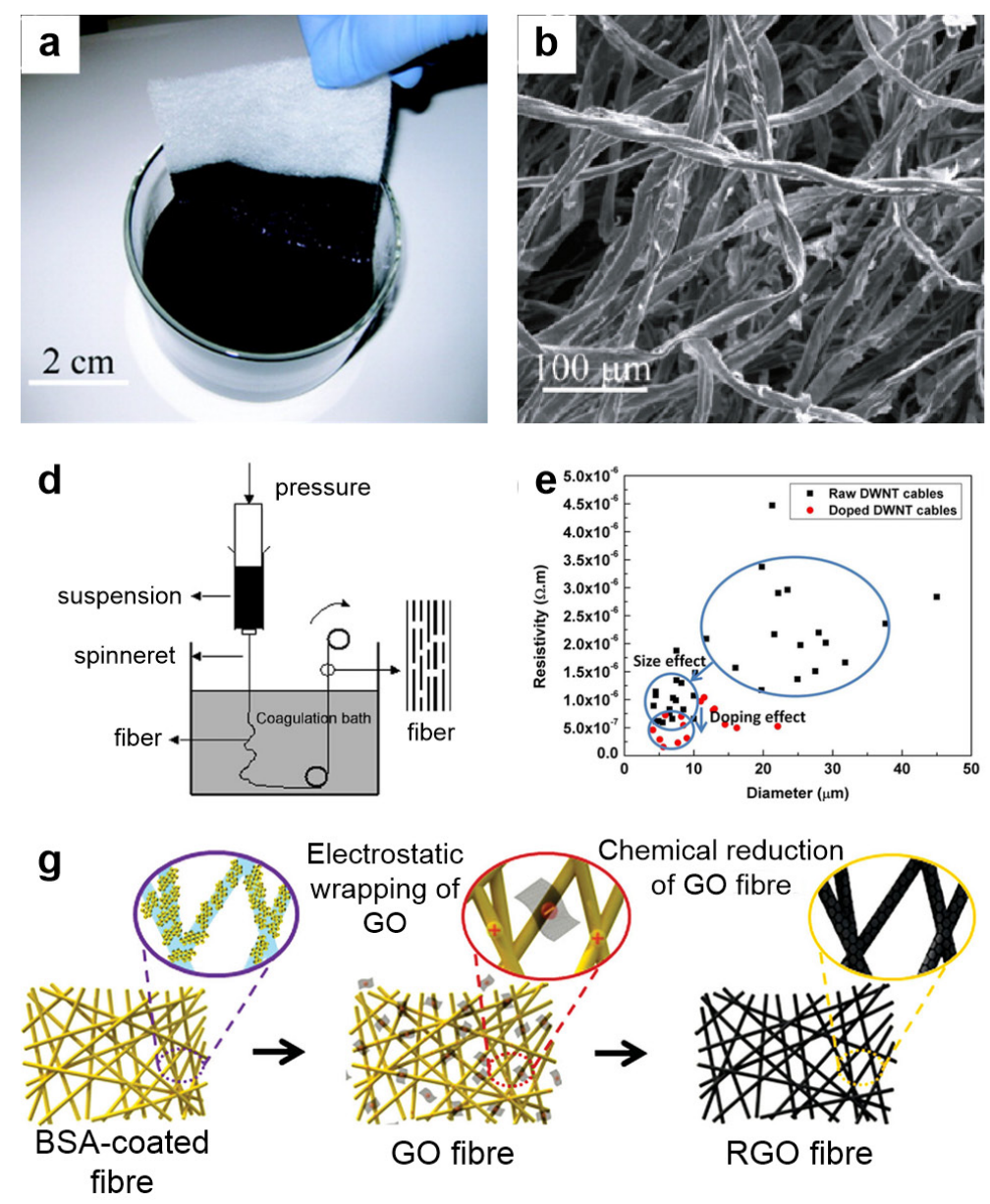
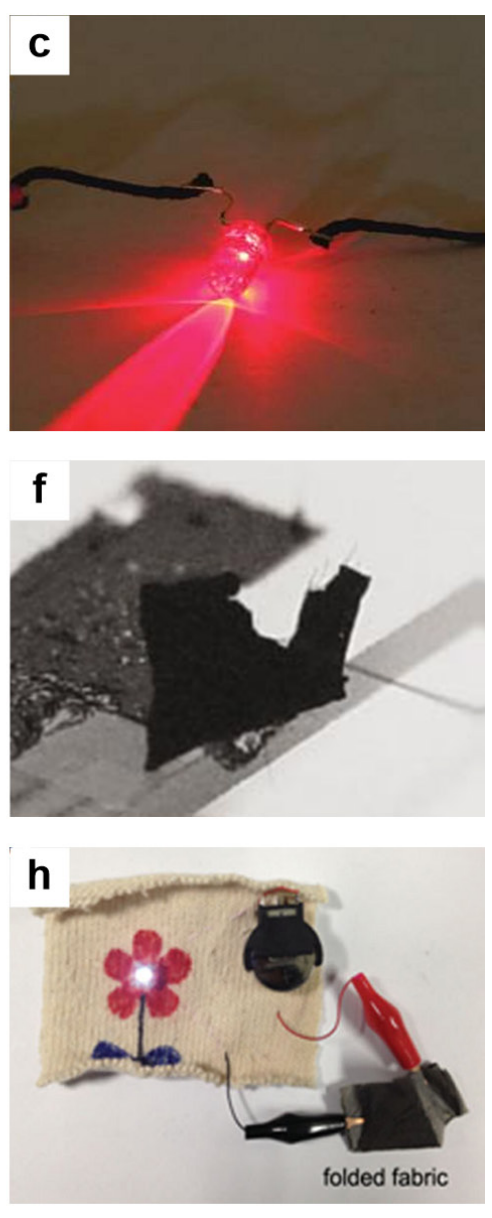

Figure 3. (a) Optical image shows the dip-coating process of fabric into single-walled carbon nanotube (SWCNT)s ink for SWCNT-based conductive fabric; (b) SEM image of a cotton sheet coated with SWNTs on the fibrous surface; (c) Demonstration of LED emission with CNT-based conductive fibers; (d) Schematic of the experimental setup of the wet spinning method for CNT-based conductive fibers; (e) Resistivity versus diameter plot for raw DWNT (double walled CNT) and iodine doped DWNT cables; (f) Image shows a free standing CNT array through which a yarn is pulling out; (g) Schematic illustration of the fabrication process of graphene oxide-based conductive fiber using electrostatic force; (h) Photograph of a LED light using a folded, reduced graphene-oxide-based conductive fabric. Reprinted from [83,87,102-105] with the permission by ACS Publications, Copyright 2010, 2008 and by John Wiley and Sons, Copyright 2008, 2013 and by Nature Publishing Group, Copyright 2002, 2011.

\subsection{Metal-Based Conductive Textiles}

Metallic materials are considered a better choice for wearable electronics because of their high conductivity [89,90]. Vacuum deposition is one of the most widely used techniques for metal deposition and is also frequently used for microfabrication processes. Sputtering or evaporation 
methods can be used to directly form a thin metal layer on the exposed surface of the fibers $[107,108]$; however, these techniques have huge drawbacks such as expensive instruments, limited sample size, and non-compatibility for batch process. Also, these methods are not suitable for depositing metal on complex structures such as porous fibers, and the deposited films are weak against repeated deformations like folding or bending. In order to avoid these issues, alternative methods must be used to synthesize metal-based conductive textiles.

Electroplated or electroless plated metals, liquid metals, and metallic nanomaterials such as nanoparticles or nanowires are considered ideal candidates in the growing field of wearable electronics $[109,110]$. Metal plating methods have been widely used to deposit metal for printed circuit boards, metallization processes in microfabrication, and corrosion protection. Figure 4a shows an SEM image of a gold-plated conductive fiber, in which Kevlar fibers were first treated with $\mathrm{Sn}^{2+}$ and $\mathrm{Pd}^{2+}$ ions followed by electroless Ni deposition for conductivity [109]. Au was then electroplated onto the surface to achieve a conductive fiber with a conductivity of $\sim 6 \mathrm{~S} / \mathrm{cm}$ and power output of $1 \mathrm{~W}$. However, the metal films are weakly attached to the surface and may separate from the fiber during further processing. To overcome these obstacles, a recent study presents a new, simple, and inexpensive chemical solution method, as shown in Figure $4 \mathrm{~b}$ [88]. In this process, an Al precursor was used to deposit $\mathrm{Al}$ on the surface of fibrous materials. Figure $4 \mathrm{c}$ shows the electrical resistances verses immersion time in the Al precursor solution, and the inset shows an LED connected to these fibers [88].

Another method of synthesizing metal-based conductive textiles is the use of liquid metals [111]. Eutectic gallium indium (EGaIn) is a liquid metal with high conductivity $\left(\sigma=3.4 \times 10^{4} \mathrm{~S} / \mathrm{cm}\right)$ and a low melting point $\left(T_{m}=15.7^{\circ} \mathrm{C}\right)$ that spontaneously forms a thin oxide layer that can be used to mold the metal into complex shapes [111]. When sufficient force is applied, the oxide layer can be damaged and the shape of the EGaIn can be changed. Zhu et al. has filled a hollow elastomer fiber with EGaIn to obtain stretchable conductors, as shown in Figure 4d [112]. The authors observed that the metallic continuity is maintained even after the applying a $700 \%$ strain.

Various metallic nanomaterials such as silver, copper, aluminum, gold, and tin are used as conductive materials for textiles [113]. Atwa et al. demonstrated nylon, polyester, and cotton threads dip-coated with Ag nanowires (AgNWs), which exhibit high mechanical flexibility and a small increase in resistance after 200 bending cycles as compared to commercial conductive fibers [113]; however, metallic nanomaterials mixed with polymers can lead to better stability. Recently, Lee et al. reported the fabrication of silver nanoparticle $(\mathrm{AgNP})$ /polymer-coated Kevlar fiber with a silver content of more than $80 \mathrm{wt} \%$ [20]. Figure 4e shows the surface morphology of the as-prepared fibers along with an inset showing the AgNPs on the surface [20]. In this work, the $\mathrm{AgCF}_{3} \mathrm{COO}$ solution was absorbed by a poly (styrene-block-butadienstyrene) (SBS) polymer and then reduced to AgNPs using hydrazine hydrate. Figure $4 \mathrm{f}$ shows the small change in resistance during 3000 folding tests [20]. In another study, Lee et al. inserted AgNWs into a stretchable AgNP/SBS structure to obtain increased conductance under strain [90]. The fiber shows high electrical conductivity, $2450 \mathrm{~S} / \mathrm{cm}$, and can stretch up to $900 \%$ strain as shown in Figure $4 \mathrm{~g}$ [90]. Table 1 presents a comparison of the properties of these metallic conductive fibers. 

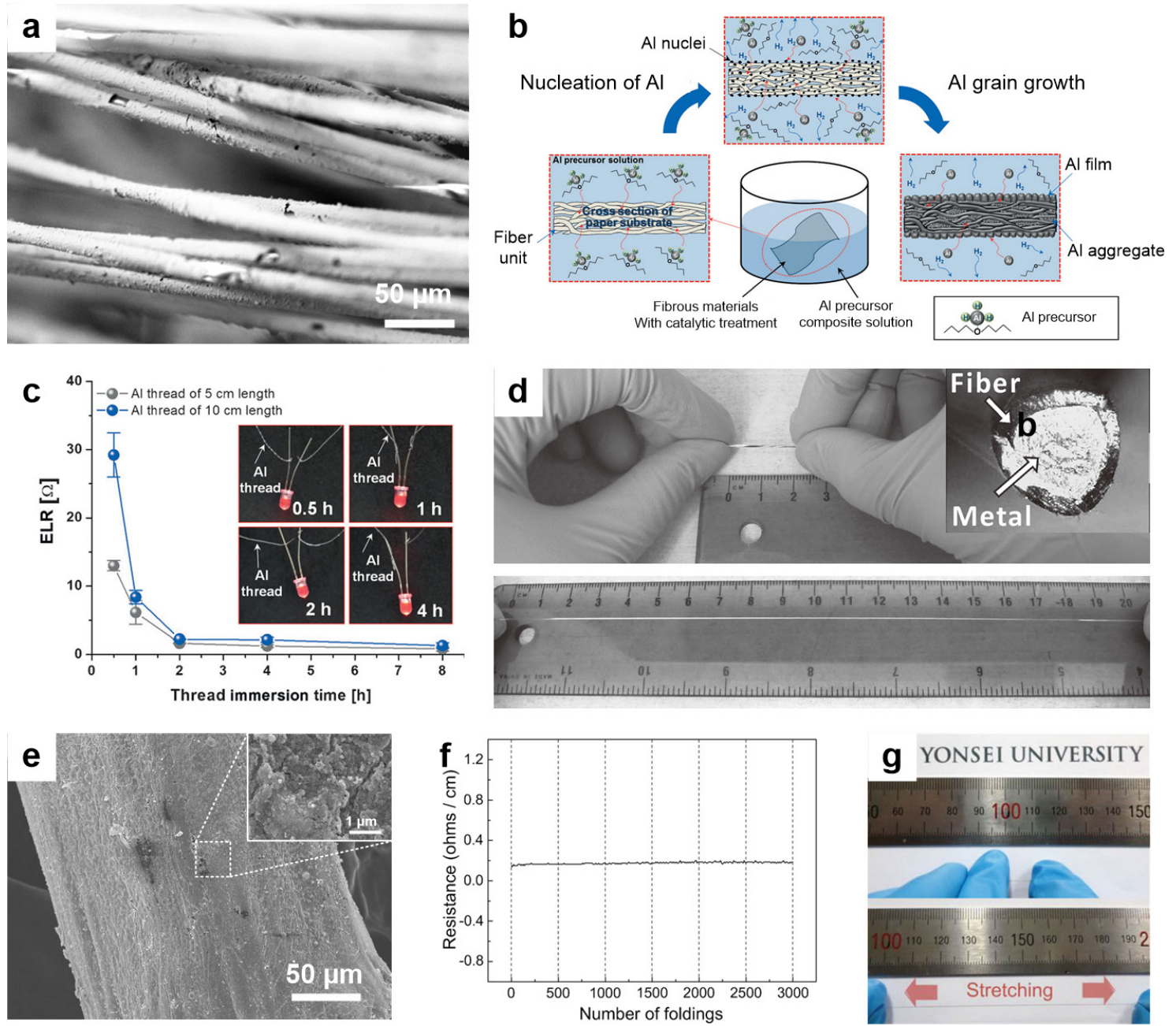

Figure 4. (a) SEM image of conductive Kevlar fibers coated with $\mathrm{Ni} / \mathrm{Au}$; (b) Schematic representation of the chemical solution process for the fabrication of conductive $\mathrm{Al}$ textiles; (c) Plot of the electrical linear resistance of Al-based conductive fiber synthesized by the chemical solution process and inset shows the functioning LEDs; (d) Optical image of unstretched and stretched (up to $20 \mathrm{~cm}$ ) conductive fiber; (e) SEM image showing the surface of the Ag nanoparticles and elastomer composite-based conductive fiber; (f) Electrical resistance change in the Ag-based conductive fiber during the 3000 cyclic folding test; (g) Optical image of pre- and 900\%-strained Ag nanoparticles and elastomer composite fibers. Reproduced from [20,88,90,109,112] with the permission by ACS Publications, Copyright 2011 and by John Wiley and Sons, Copyright 2013, 2013, 2015, 2015.

\section{Textile Electronic Components}

Textile-based electronic devices require electronic functionalities on fiber/textile materials with robust mechanical properties. In this section, we will discuss electronic devices based on fibers and their use in textile electronics. The operation of electronic devices and their stability in a textile system will be explored in detail. Specifically, we will demonstrate recent developments in textile-based electronic devices such as transistors, light emitting diodes (LEDs), and sensors. 


\subsection{Transistor}

The integration of electronic devices into textiles at the fiber level is vital to the future of wearable electronics. There are various aspects to be considered before employing electronic devices into a textile-based system such as materials, structures, and the compatibility of electronic devices with textile fabrics. As a fundamental building block of electronic devices, transistors must be integrated into fabric or textiles. In this section, we briefly introduce fiber or textile-based transistors and their operation. In general, an electronic device that can amplify and convert electronic signal to electrical power is known as transistor. Since transistors are basic components in electronic devices, the integration of transistors into fabric or textile systems is highly important. However, conventional inorganic FETs cannot be applied to fabric or textile-based electronics due to flexibility issues and limitations in the fabrication process. Given the technological limitations of inorganic materials, organic thin film transistors (OTFTs) have received significant attention owing to their flexibility, compatibility with flexible electronics, light weight, biocompatibility, low cost, and low-temperature process capability [114-117].

Organic-based transistors due to their flexibility, easy fabrication process and comparable electrical performance (as compared to inorganic TFTs) are desirable in textile industry [118-120]. Two types of fiber-based OTFTs have been reported; fiber organic field effect transistors (F-OFETs) and organic electrochemical transistors (OECTs) [121]. The working principle of F-OFETs is similar to that of commercial FETs. In O-FETs, organic thin-film semiconductors are used as an active layer instead of inorganic materials. Figure 5a shows a schematic diagram of F-OFETs. Here, a commercially available cylindrical metal fiber ( $\mathrm{Al} \&$ stainless steel) is insulated using a uniform layer of polyimide, followed by the evaporation of pentacene as an active material PEDOT:PSS is then deposited on the pentacene surface using a soft lithographic process to form source and drain electrodes. Figure 5b,c shows an optical microscope image of the channel length $(\sim 45 \mu \mathrm{m})$ and corresponding $I_{\mathrm{D}}-V_{\mathrm{D}}$ curve of an F-OFET [122]. In spite of the low value of the width/length ratio of the F-OFET, the on current and on-off ratio are reasonably high $\left(\sim 10^{4}\right)$, which is fully comparable with those of planar devices. Although F-OFETs exhibit decent electrical properties, they suffer from significant disadvantages such as high operating voltages, high equipment cost, and a complicated fabrication process. OECTs have been considered as an alternative to F-OFETs, since they can be fabricated on the basis of fiber structure. The working principle of OECTs is based on the electro-chemical process, where a reversible process of doping and de-doping of electronic polymers allows the transistor to operate. Figure 5d shows a schematic picture of OECTs on a planar substrate [123]. Here, source (S), drain (D), and gate $(\mathrm{G})$ electrodes are demonstrated on flat substrates such as glass, plastic, and paper. The conducting polymer PEDOT/PSS films are first micro-patterned on a flat substrate, and are followed by the pattering of an electrolyte (micro-channel of $\sim 3 \mu \mathrm{m}$ height and $\sim 15 \mu \mathrm{m}$ width) over the patterned PEDOT/PSS film. 
a

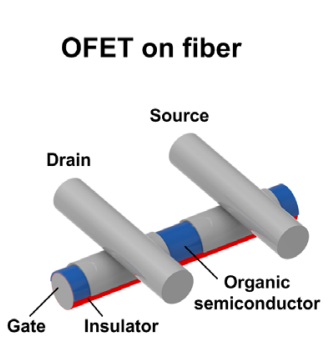

Organic field effect transistor (OFET)

b

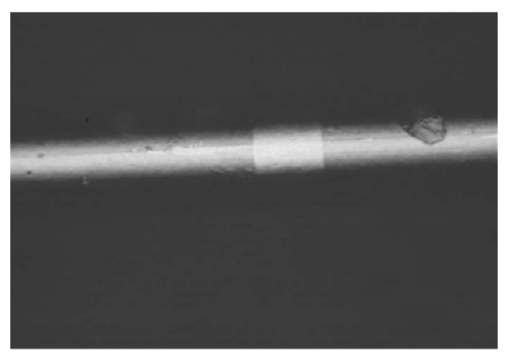

C

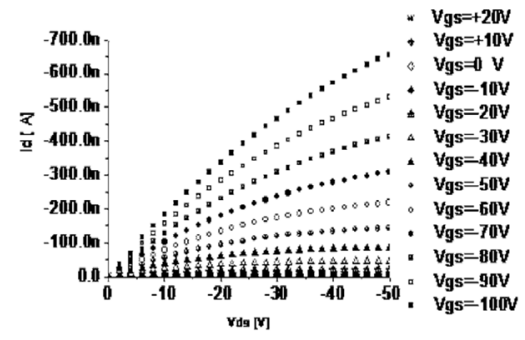

\section{Organic electrochemical transistor (OECT)}

d

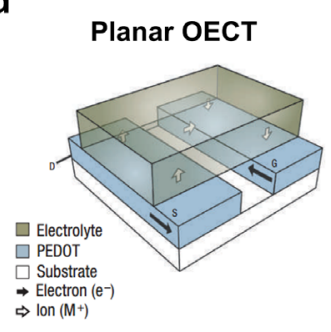

g

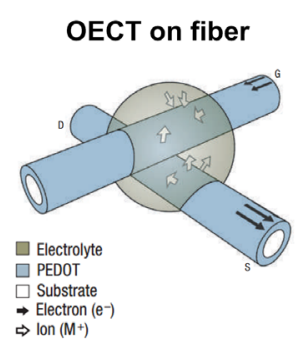

e

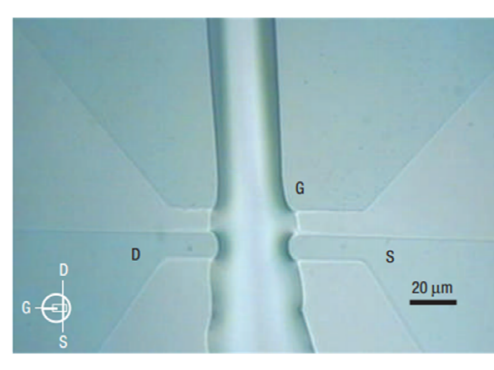

h

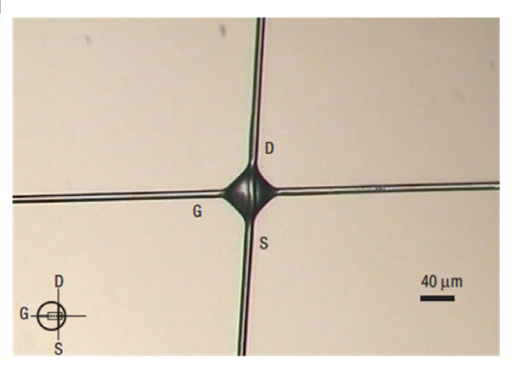

f

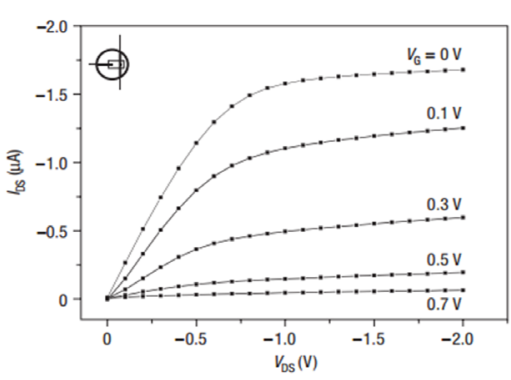

i

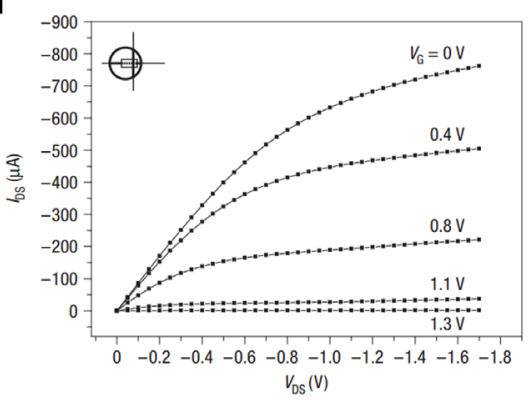

Figure 5. (a) Schematic picture of the organic field effect transistor (O-FET); (b) Optical image showing channel area; (c) The output characteristic of O-FET; (d) Schematic picture of a planar OECT; (e) Optical micrograph of a planar organic electrochemical transistor (OECT); (f) Output characteristic of a planar OECT; (g) Schematic picture of a fiber OECT; (h) Optical micrograph of a fiber OECT; (i) Output characteristic of a fiber OECT. Reprinted from [122,123] with permissions by AIP Publishing LLC, Copyright 2006 and by Nature Publishing Group, Copyright 2007.

An optical micrograph of this configuration is shown in Figure 5e, and the corresponding output characteristic of a planar ECT is shown in Figure 5f [123]. The output characteristics clearly indicate that the current is saturated with increasing drain voltage, and that the gate voltage is low compared to that of F-OFETs. When the gate voltage is zero, the transistor is in the ON state, while the gate voltage transistor moves to the OFF state when the gate voltage is further increased, as shown in Figure $5 \mathrm{f}$. In order to fabricate OECTs on a fiber structure, a simple new method was performed by Hamedi et al. [123]. Figure $5 \mathrm{~g}$ shows a schematic picture of a fiber OECT constructed using PEDOT-coated polyamide fibers $(\sim 10 \mu \mathrm{m}$ diameter). Two PEDOT-coated fibers are kept in a cross geometry and an electrolyte is dropped at the fiber junction, as shown in the optical image in Figure 5h [123]. In this cross geometry, one PEDOT-coated fiber acts as source and drain and the other as gate electrode. An active material (electrolyte with $33 \mathrm{wt} \%$ PSS, $12 \mathrm{wt} \%$ glycol, $8 \mathrm{wt} \%$ sorbitol, water and $0.1 \mathrm{M} \mathrm{NaClO}_{4}$ ) acts as a 
conducting channel, which is controlled by the gate electrode. In this way, micrometer-sized fiber OECTs can be easily integrated into textiles. The output characteristics of fiber OECTs are similar to planer OECTs, as shown in Figure 5i [123]. The similar electrical characteristics between fiber OECTs and planer OECTs are attributed to the fact that the operation of electrochemical transistor is dominated by the interface effect between the conducting polymer and electrolyte. Therefore, fiber OECTs can be used as effective transistors in spite of completely different geometry when compared to planar OECTs. Theoretically, the fiber OECTs could be used for large scale production: $\sim 100,000$ transistors $/ \mathrm{cm}^{2}$ can be constructed using $10 \mu \mathrm{m}$ fibers. Also, the authors have fabricated a binary tree multiplexer structure by using these fiber OECTs. This multiplexer is able to encode the information from a large number of data sources into a single channel. Hamedi et al. fabricated a fiber-based OECT using poly 3-hexylthiophene (P3HT) with $100 \mu \mathrm{m}$ channel length and showed that the fiber can be operated below $\sim 1 \mathrm{~V}$ [124].

Since fiber OECTs have many advantages such as low operating voltages, large amounts of current densities, and low cost production, they can easily replace OFETs and can be integrated to wearable electronics by directly weaving them into fabrics. Bonderover et al. have demonstrated textile inverters made by weaving fiber-based transistors [125]. They have shown that E-textiles with electronic components can be designed by simply woven fibers. Thus, in the future it is possible to fabricate such E-textiles. However, their long response time and low switching frequency remain significant hurdles. In addition, the exact charge transport mechanism of fabric OECTs must be revealed to fully understand the operation process.

\subsection{Light-Emitting Diodes}

A light emitting diode (LED) is a semiconductor device that emits visible light when electron hole recombination takes places inside the device. Since the first commercial infrared inorganic LED was presented by Holonyak et al. in 1962 [126], various LEDs have been developed around the world such as visible, ultraviolet, and infrared LEDs [127-131]. Since a solid semiconductor material is generally used to generate light in LEDs, LEDs were originally considered solid-state devices. A breakthrough occurred in 1987 when Tang and Van Slyke reported a new type of LED based on organic semiconductors [132]. Organic LEDs (OLEDs) have several advantages, including lower manufacturing cost, faster response time, potential flexibility, low power consumption, and less heat dissipation [133]. Since OLEDs are malleable, they can be compatible with flexible substrates and can be applied to wearable electronics. Current research into OLEDs focuses primarily on two-dimensional (2D) devices, however, one-dimensional (1D) OLEDs have begun to receive attention for future wearable electronics. In this section, various 1D fiber-based OLEDs will be discussed.

Connor et al. fabricated a fiber-based OLED using molecular organic compound as an active layer [134]. The inherently-flexible nature of molecular organic compounds is compatible with fiber structure. Figure 6 a shows a schematic illustration of the fiber-based OLED structure used in this study [134]. Here, a polyimide-coated silica fiber was prepared as a substrate, and emission layers and organic charge transport layers were deposited between the anode and cathode electrodes via a vacuum thermal evaporation technique. A photograph of a $1 \mathrm{~mm}$ segment of green-light OLED on fiber clearly shows the emitting characteristics of green light. For a performance comparison of electricity and 
luminescence between a fiber-based OLED and planar OLED, they fabricated a planar OLED using a planar silicon/polyimide substrate and investigated the electrical and luminescence characteristics. The electrical and luminescence characteristics of fiber-based OLEDs showed comparable results to planar OLEDs; however, a slightly larger leakage current was measured at low bias due to the surface roughness of the fiber structure. In addition, the fiber is rather thick at $\sim 480 \mu \mathrm{m}$, which can hinder practical use. Yang et al. recently fabricated single core-shell fiber OLEDs based on an ionic transition-metal complex (iTMC) using a coaxial electrospinning process [135]. A galinstan liquid metal core and a ruthenium tris (bipyridine) with poly (ethyl-oxide) (PEO) mixture shell were co-electrospun to from the cathode and electroluminescent layer, respectively. The anode was formed via thermal evaporation of indium tin oxide. Figure $6 \mathrm{~b}$ shows a schematic illustration and optical image of an emitting iTMC [135]. The device was initially turned on at $4.2 \mathrm{~V}$ and bright electroluminescent was observed at $6.8 \mathrm{~V}$. This work shows the possibility of direct fabrication of 1D flexible OLEDs without flexible substrates; however, the efficiency or brightness of the devices is not clearly shown.

Vohra et al. fabricated luminescent F8BT/PEO nanofibers using electrospinning [43]. Figure 6c shows a schematic illustration and fluorescence microscopy image of the conjugated polymer electrospun nanofiber-based OLED [43]. To fabricate the device, a thin layer of PEDOT-PSS was spin coated onto the ITO/glass substrates, and the F8BT/PEO nanofibers were directly collected onto the resulting layer. Then, a PVK (poly $N$-vinylcarbazole) solution was spin coated on top, and finally a thin layer of calcium and aluminum were evaporated. Here, the PVK-coated F8BT/PEO nanofibers functioned as an active layer. This work solved the charge injection issue in organic nanofibers by annealing the device at $150{ }^{\circ} \mathrm{C}$, which changed the active layer into ribbon-like morphology. The measured external quantum efficiencies and luminance were $0.5 \%$ and $2300 \mathrm{~cd} \cdot \mathrm{m}^{-2}$ at $6 \mathrm{~V}$, respectively.

Most recently, Zhang et al. developed a color-tunable and wearable fiber-shaped polymer light emitting electrochemical cell (PLEC), which allows for the integration of wearable LEDs in textiles [42]. The fiber-shaped PLEC was fabricated using an all-solution processing method, which increases the chance for practical use. Figure $6 \mathrm{~d}$ presents a schematic diagram of a flexible fiber-based PLEC [42]. To fabricate the fiber-shaped PLEC, a stainless steel wire was dip coated with $\mathrm{ZnO}$ nanoparticles to form an electron transfer layer and decrease leakage current. Then, an electroluminescent polymer layer (a blend of PF-B, ethoxylated trimethylopropane triacrylate and lithium trifluoromethane sulphonate) was grafted over the $\mathrm{ZnO}$-coated stainless steel wire, followed by wrapping the modified steel wire with the aligned carbon nanotube (CNT) sheet. The aligned CNT provided high electrical conductivity and flexibility in the device. Since the fiber-shaped PLEC is a 1D structure, the brightness was the same in all directions. In addition, the authors successfully integrated PLECs into fabrics and showed the tunable colors. This work shows promising benefits such as flexibility, light weight, high brightness that is maintained after bending, and tunable colors, as well as the possibility of integration into wearable electronic devices. 
a

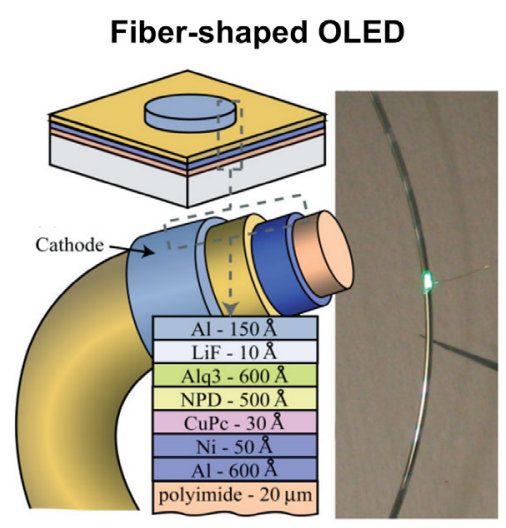

c

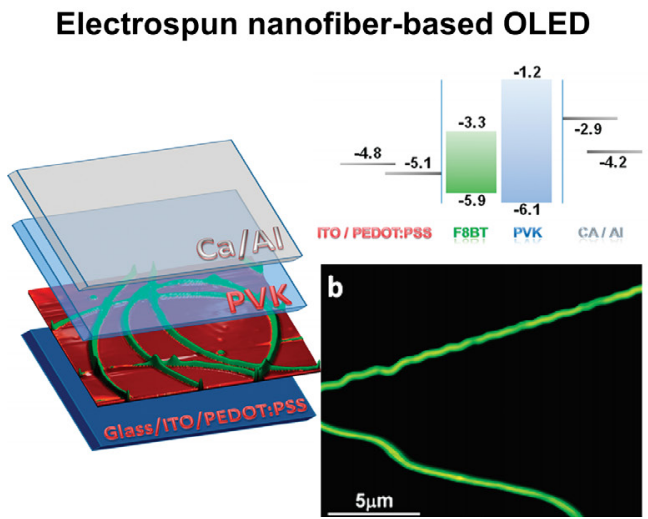

b

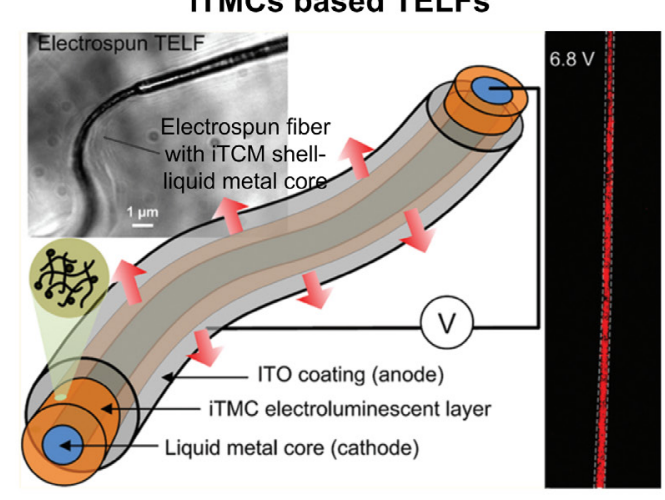

d

Flexible fiber-shaped PLECs

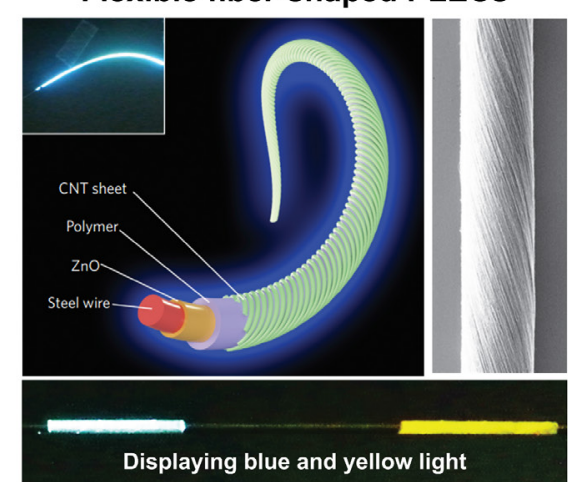

Figure 6. (a) Schematic illustration of a fiber-shaped organic light emitting diodes (OLED) structure compared with a typical OLED structure and a photograph of a flexed fiber with a green light-emitting pixel; (b) Schematic illustration and optical image of ionic transition-metal complex (iTMCs)-based electro-luminescent nanofibers (TELFs) fabricated via coelectrospinning and luminescence response of TELF under an applied voltage of $6.8 \mathrm{~V}$; (c) Schematic of the conjugated polymer electrospun nanofiber-based OLED structure (left), energy level diagram (right top), and fluorescence microscopy image of an electrospun nanofiber, F8BT-PEO (right bottom); (d) Schematic illustration showing the structure of flexible fiber-shaped polymer light-emitting electrochemical cells (PLECs). Left inset: photograph of a fiber-shaped PLEC biased at $10 \mathrm{~V}$, right inset: aligned CNT sheet wrapped around the modified stainless steel wire, and bottom inset: PLEC displaying blue and yellow light. Reproduced from [42,43,134,135] with permissions by John Wiley \& Sons, Copyright 2007 and by ACS Publications, Copyright 2012, 2011 and by Nature Publishing group, Copyright 2015.

\subsection{High Sensitivity Sensors}

Sensors are widely used electronic devices which detect specific the characteristics of their surroundings and are present in a wide variety of applications such as electronics, aerospace, medicine, robotics, and machinery [136-142]. Types of sensors include temperature, pressure, humidity, gravity, sound, and vibration sensors [143-150]. In this review, we focus on textile-based pressure sensors, as sensing pressure is one of the most important functions of wearable electronics. 
In 1996, a full-body, soft, flexible sensing suit was developed for a small robot by Japanese researchers [151]. They used an electrically-conductive fabric sheet and conductive strings with a spacer, and measured the contact resistance after applying pressure, demonstrating a promising remote robot sensor capable of controlling robotic body interactions. Shimojo et al. fabricated a tactile sensor using pressure-conductive rubber [152] via the development of a thin, flexible, attachable, tactile sensor that can be operated on curved surfaces. They measured the change in resistance under constant strain, observing a change in resistance during a period of $100 \mathrm{~s}$. Their tactile sensor, when properly operated on a robot hand, showed good durability under repeated bending tests. Takamatsu et al. developed a large-area pressure sensor on a meter-scale using dye-coated conductive polymer (PEDOT:PSS) and perfluoropolymer dielectric film [153]. The sensor was constructed by weaving fibers into an area of $16 \times 16 \mathrm{~cm}^{2}$. The sensitivity of this design ranged from 0.98 to $9.8 \mathrm{~N} / \mathrm{cm}^{2}$, sensitive enough to detect human touch and therefore suitable for wearable keyboards and healthcare systems.

Recently, Lee et al. fabricated a textile-based pressure sensor using Ag-SBS composite conductive fibers [20]. A capacitive type of textile-based sensor was fabricated using a poly(dimethyl-siloxane) (PDMS) coating on the conductive fiber and cross-stacking two PDMS-coated fibers, as shown in Figure 7a [20]. Figure $7 \mathrm{~b}$ shows the relative changes in capacitance of fiber-based pressure sensors via increasing loads of applied pressure [20]. In this operation, the conductive fiber-based pressure sensor showed stable responses to the various loads (Figure 7c), and detected the loading and unloading of grains of extremely low weight. This work further demonstrates e-textile applications with conductive fiber-based pressure sensors. The textile-based pressure sensor was pixelated through weaving techniques and detected the spatial distribution of external pressures, as shown in Figure 7d [20]. This textile-based pressure sensor was also sewn into a smart glove and clothes and showed the control of drone and spider robots, as shown in Figure 7e [20]. This work demonstrates that human-machine interfaces can be successfully operated using wearable textile-based pressure sensors with ultrahigh sensitivity and stability.

Ma et al. presented a new means of fabricating stretchable fabric [154]. To make stretchable knitted fabric, conductive stretchable fibers were first fabricated via wet-spinning. Figure 8 a shows the surface morphology of conductive stretchable fibers composed of Ag nanoparticles, nAg-MWCNTs, and poly (vinylidene fluoride-co-hexafluoropropylene) (PVDF-HFP) matrix [154]. Stretchable fabric was then made by knitting the conductive stretchable fibers. The knitted fabric showed reversible characteristics under $100 \%$ tensile strain with mechanical and electrical stability (Figure 8b) [154]. In addition, the stretchable fabric was applied to a robotic finger system and demonstrated feasibility for practical application. 
a

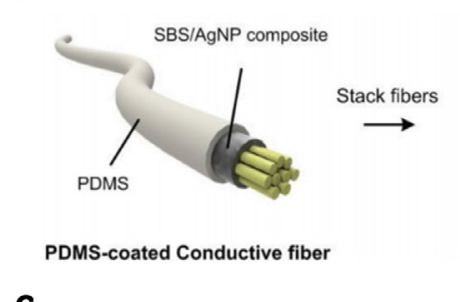

C

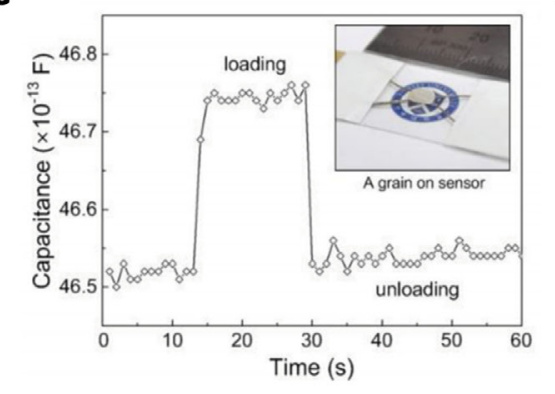

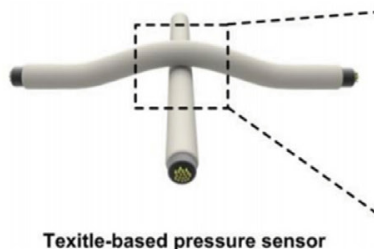

d

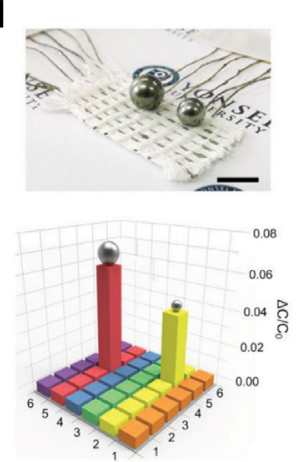

b

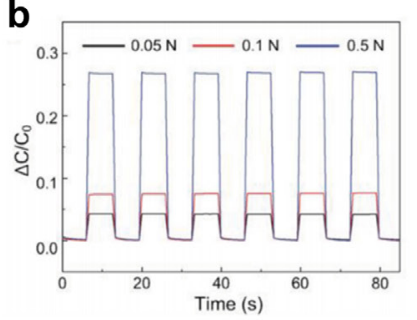

e

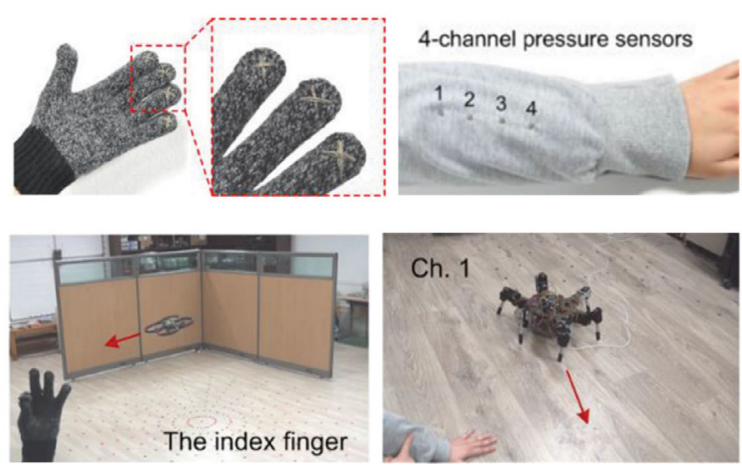

Figure 7. (a) Schematic structure of a textile-based pressure sensor fabricated with PDMS-coated conductive fibers; (b) Capacitive response of the pressure sensor for the various applied loads; (c) Capacitive response of the pressure sensor to the placing and removal of a grain $(8 \mathrm{mg}$ ); (d) Fabrication of pixelated pressure sensor array; (e) Photographs of the smart glove and clothes with textile-based pressure sensors and operation using smart glove and clothes to control the drone and spider robot. Reprinted from [20] with permissions by John Wiley \& Sons, Copyright 2015.

More recently, Lee et al. fabricated highly-stretchable conductive fibers composed of Ag nanowires (Ag NWs), Ag nanoparticles (Ag NPs), and SBS polymer using the wet spinning method [90]. Ag NWs allow for significant stretching capability in the fabric because they are aligned along the applied uniaxial strain and bridge the disconnected networks of Ag NPs inside the fiber, as shown in Figure 8c [90].

Figure $8 \mathrm{~d}$ shows changes in conductivities with regard to various applied tensile strains [90]. As tensile strain increased, conductivities initially decreased, but improved again with increased strain. The reliability test showed stable operation under a repeatable bending test (Figure 8e) [90]. The authors further demonstrated the capability of detecting human motion using the fabricated stretchable sensor. The smart glove was integrated with fibers on each finger and successfully detected finger sign language. Figure $8 \mathrm{f}$ shows the detection of the letters " $\mathrm{Y}$ " and " $\mathrm{S}$ " via the bending of fingers [90]. 
a

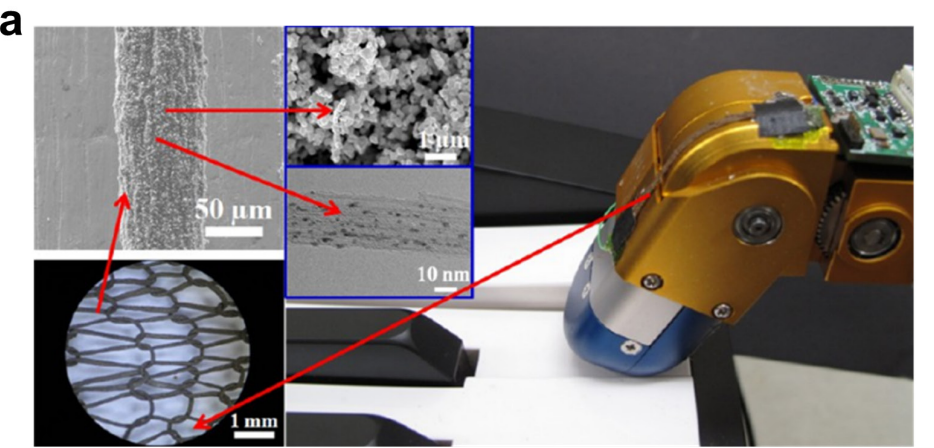

C

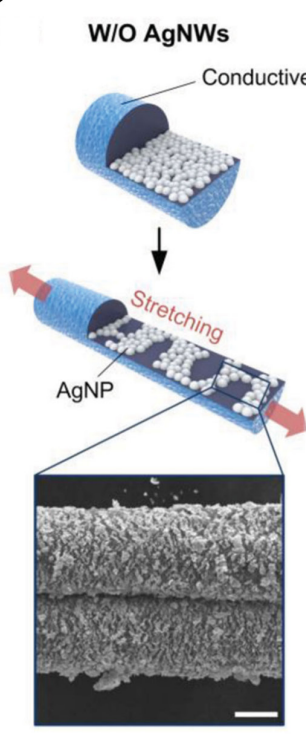

d

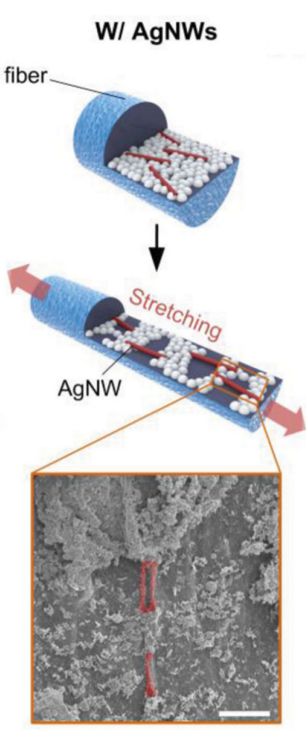

b

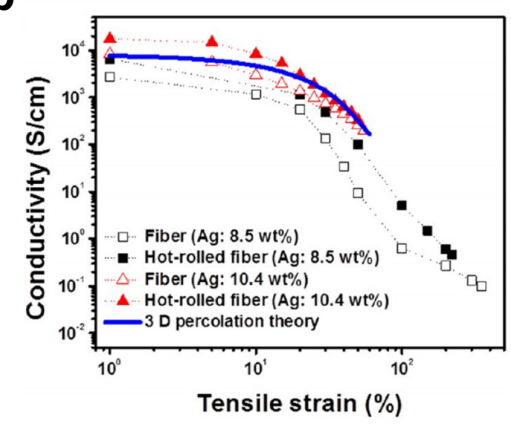

f

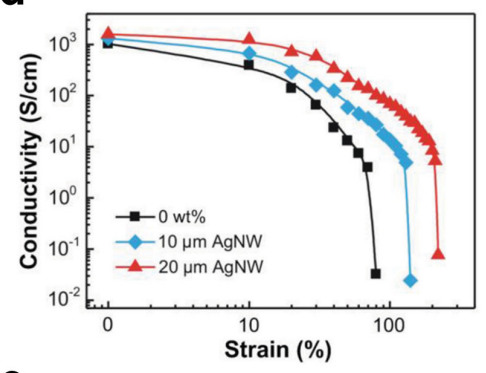

e

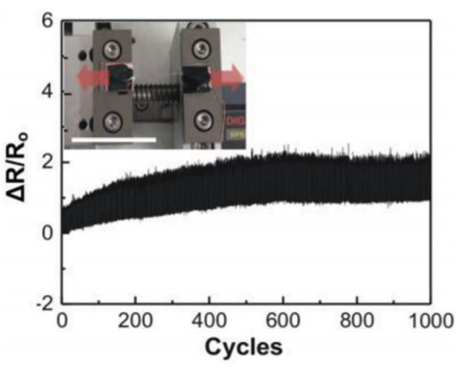

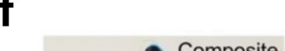
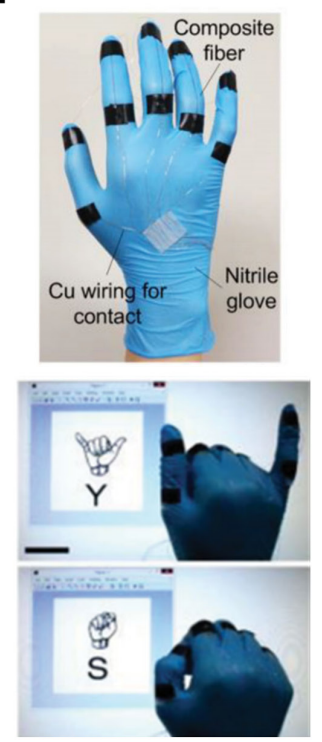

Figure 8. (a) FE-SEM and HRTEM images of knitted fabrics made from highly-conductive stretchable fibers. Bottom of this image shows an optical image of 2 ply rope. The knitted fabric was attached to a robot finger (as shown by arrow) for touch sensing; (b) Plot shows the conductivities of fibers as a function of tensile strain; (c) Schematic illustration of silver nanowires (AgNWs) and silver nanoparticles (AgNPs) in the composite fiber. (Left bottom image in navy colour line: SEM image of AgNP-mixed styrene-block-butadienstyrene (SBS) fiber without AgNWs at 50\% strain and and Right bottom image in red colour line: SEM images of the AgNW-AgNP embedded SBS fiber at 50\% strain); (d) Changes in conductivity of the composite fiber depending on the length of the AgNWs; (e) Reliability test measured the changes in the normalized resistance of the composite fiber; (f) Photograph of a smart glove made with composite fibers and motion detection of English letters using a sign language. Reproduced from [90,154] with permissions by ACS Publications, Copyright 2014 and by John Wiley \& Sons, Copyright 2015.

\section{Textile-Based Energy Applications: Energy Harvesting \& Storage}

Although commercial energy harvesting and storage devices using semiconducting thin film exhibit high performance, they also have limitations including their complex fabrication process and high cost. Recent novel materials investigated for energy related devices include dye, organic and inorganic polymers with high efficiency, large capacity, abundant material sources, easy fabrication, and 
flexibility. Along with the development of materials for energy devices, there are several studies on novel methods for energy harvesting using the human body, such as piezoelectric, triboelectric, and thermoelectric nanogenerators. Nanogenerators can provide self-powered systems that are useful in wireless devices. In particular, fiber-based nanogenerators have been primarily studied in the form of twisted, conjugated, or weaved multiple fiber electrodes integrated with supercapacitors.

\subsection{Energy Harvesting from Human Motion}

As the number of applications related to mobile electronic devices increases drastically, the development of long-lasting power sources for these devices is increasingly in demand. Sustainable self-powered sources have received significant attention as alternatives to conventional rechargeable batteries. Recently, energy harvesting from human body motions has proven a new means of operating many mobile electronic devices without the need for external power sources [155].

The piezoelectric effect is a unique ability of materials with polarization domains or non-centrosymmetric structures. These materials can generate an electrical charge in response to mechanical stresses such as compression, twisting, or distortion. One novel approach using the piezoelectric effect converts human mechanical motion into electrical energy. Wang et al. demonstrated that ultrasonic waves were converted into electricity using a Pt-coated zigzag electrode with vertically-aligned $\mathrm{ZnO}$ nanowires (NWs) [156]. They optimized the size and shape of the ZnO NWs and obtained high-output power per unit of area reaching $\sim 10 \mu \mathrm{W} / \mathrm{cm}^{2}$. The generated energy can potentially facilitate long-term sensors that are applicable to mobile electronic devices and systems [157]. Zhang et al. reported a flexible nanogenerator (FNG) fabricated using $\mathrm{BaTiO}_{3}$ nanowire and polyvinyl chloride (PVC) composite piezoelectric fiber [158]. After optimizing their process parameters, they placed FNG on a bent human arm, producing voltage and current outputs up to $1.9 \mathrm{~V}$ and $24 \mathrm{nA}$, respectively. Several methods have been developed for harvesting electrical energy by converting mechanical energy into electricity using piezoelectric materials [159]. A prototype electrostatic non-resonant generator has been designed and optimized by Mitcheson et al. [160]. Using flexible polymer membranes, they can generate an output voltage of $250 \mathrm{~V}$ when the generator is pre-charged to $30 \mathrm{~V}$. Qin et al. have described the concept of textile-based piezoelectric nanogenerators that can harvest electrical energy from the friction between two fibers [161]. Although only a small amount of output current $(\sim \pm 5 \mathrm{pA})$ was obtained during the pulling/releasing cycles of the nanogenerator, they established a novel method of energy harvesting using fabrics.

Further, Jeong et al. reported a novel approach to fabricating a high-performance hyper-stretchable nanogenerator (SEG) with extremely long Ag NWs [162]. The hyper-stretchable piezoelectric elastic composite (PEC) rubber polymer was composed of very long nanowire percolation (VLNP) electrodes and a well-dispersed mixture of lead magnesioniobate lead titanate (PMN-PT) particles and multi-walled carbon nanotubes (MWCNTs). The composite exhibited high stretchability over $200 \%$ strain without any mechanical cracking; this could be attributed to variation in the piezoelectric dipoles in the PEC caused by stretching, and helps accumulate electrons, generating voltage and current. An open-circuit voltage $(\sim 4 \mathrm{~V})$ and short-circuit current $(\sim 500 \mathrm{nA})$ were obtained and the generated energy can sufficiently operate commercial electronic units. The SEG was tested in biological motion after being sewn onto the knee of a stretchable stocking, as shown in Figure 9a,b [162]. However, textile-type 
energy harvesters seem to face some prevalent problems such as low energy conversion efficiency, wide spectra of vibration frequencies, and time-dependent amplitudes.

Recently, triboelectric nanogenerators (TENG) have been developed that can harvest electrical energy from mechanical friction, exhibiting high performance, a simple fabrication process, cost-effectiveness and green technology [163-166]. The principle of TENG operation is the combination of triboelectric and electrostatic induction [166,167]. When two different polymer surfaces are rubbed or compressed, opposite sign electrostatic charges are generated on each surface of the polymer films. Due to the formation of a dipole layer, triboelectric potential in TENG is generated and drives electrical charges through the external load, resulting in the generation of an open circuit voltage and a short circuit current. Lee et al. reported a textile, substrate-based triboelectric nanogenerator (T-TENG) fabricated using an assembly of Au-coated fabric and polydimethylsiloxane (PDMS) [165]. To enhance the surface friction energy, thermally-evaporated Al nanoparticles (NPs) were conjugated with Au-coated textile top electrodes. Triboelectric energy was generated when two textile electrodes were repeatedly compressed and released. The validation of T-TENG in energy harvesting using human motion was further examined on a human arm. To utilize this device in practice, they demonstrated that the alternating current (ac) output signals obtained from the T-TENG were converted to direct current (dc) using a bridge rectifier. Using the rectified dc current, a commercial capacitor was charged and a light-emitting diode (LED) was turned on. When the T-TENG attached to the human arm was bent and released, the generated output voltage and current were $139 \mathrm{~V}$ and $39 \mu \mathrm{A}$, respectively. The high efficiency can be attributed to enhanced surface roughness induced by uniformly-distributed Al NPs on the textile electrodes.

The abovementioned nanogenerators were produced on flexible, metallic-based electrodes. However, to realize the true potential of wearable electronics, it is necessary to study textile-based flexible energy harvesters without metal electrodes. Metal-free, fiber-based TENG capable of converting biomechanical motion into electricity were introduced by Zhong et al. [163]. The TENG were produced using two kinds of pretreated cotton threads, each coated with multi-walled carbon nanotubes (CNT) and polytetrafluoroethylene-carbon nanotubes. These two fibers were entangled with each other to form a light-weight and flexible fiber-based generator (FBG). When the entangled fibers were stretched, the inter-fiber gap was reduced and the CNT layer on the CNT-coated cotton thread (CCT) became positively charged due to induction, creating free electrons. Woven FBG was applied to a "power shirt" with a wireless temperature sensor capable of charging to a capacity of $10 \mathrm{nF}$, as shown in Figure 9c [163]. Figure 9d shows that the rectified DC voltage obtained from the FBG was $2.4 \mathrm{~V}$ with the charging time of $27 \mathrm{~s}$, showing that the FBG is capable of lighting a red LED. Since the fabricated power shirt can monitor body temperature cost-effectively due to the self-powered TENG system, it makes viable the possibility of woven textiles in the field of mobile medical systems. 

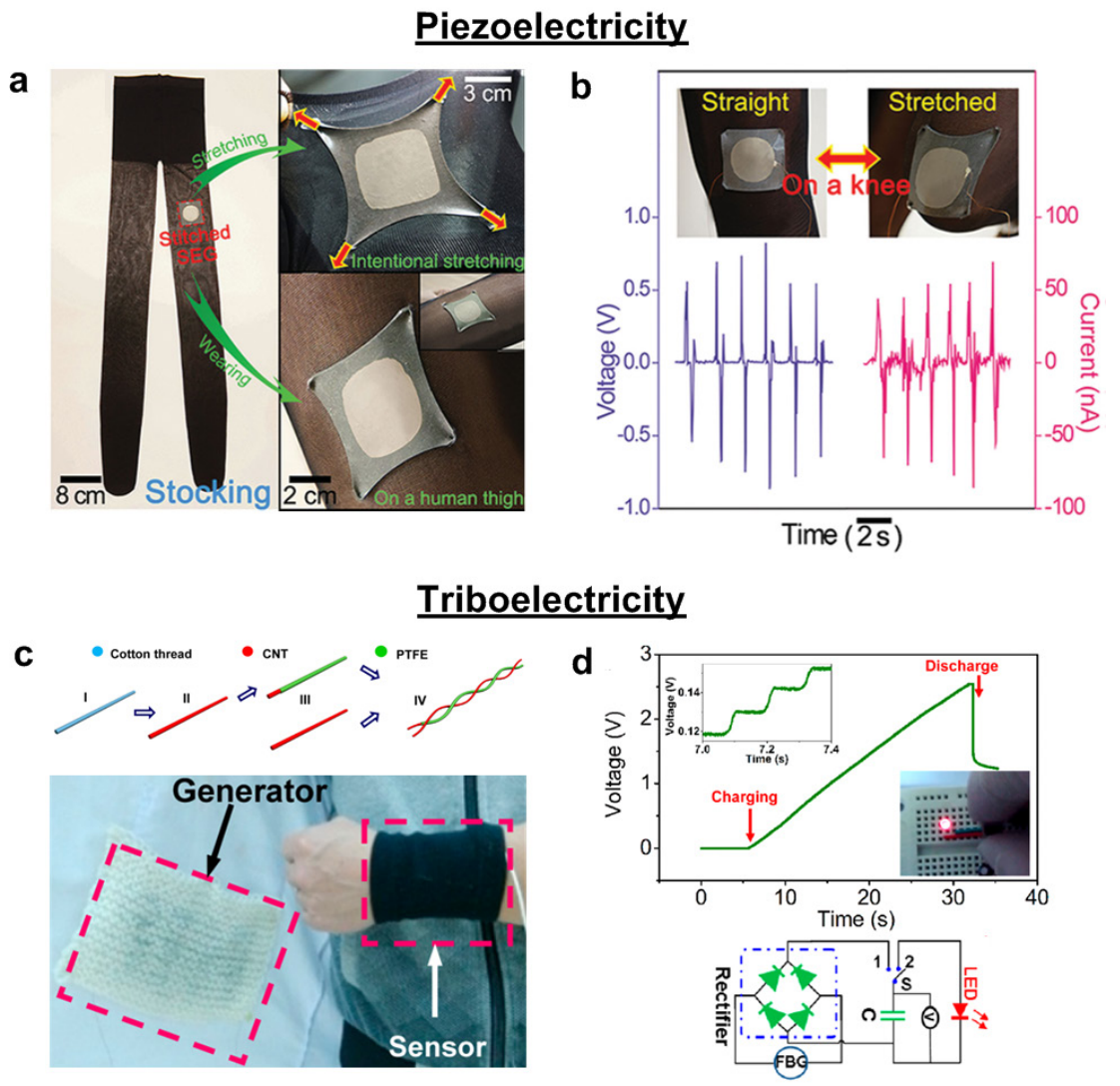

Thermoelectricity
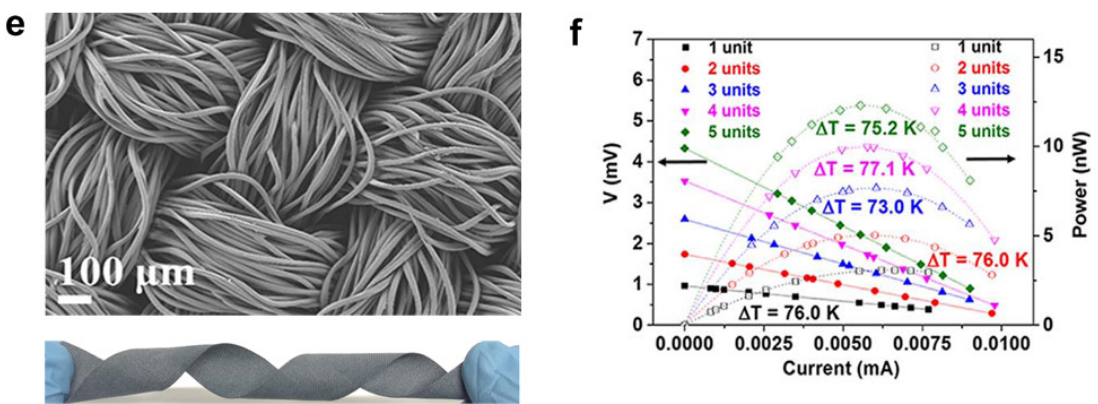

Figure 9. (a) Digital photographs of the stretchable elastic-composite generator (SEG) stitched on a nylon stocking. Photograph of the SEG intentionally stretched and fitted over a human thigh; (b) Stretching on human knees and the generated voltage and current from the SEG on the stocking by bending and straightening the knee; (c) Schematic diagram illustrating the detailed fabrication process of a fiber-based generator (above) and woven fabric FBG sewed on a lab coat (below); (d) The voltage charging curve of the $2.2 \mu \mathrm{F}$ commercial capacitor by the "power shirt" and typical bridge rectifier circuit for transforming alternating current to direct current; (e) SEM image (above) and digital photography (below) of the polyester fabric after PEDOT:PSS coating; (f) Experimental results of output voltage and power as a function of current for the fabricated devices. Current-power curves are parabolic for all devices. Reproduced from $[162,163,168]$ with permissions by John Wiley \& Sons, Copyright 2015 and by ACS Publications, Copyright 2014 and by Nature Publishing Group, Copyright 2014. 
Recently, interest in thermoelectric materials has increased due to their ability to generate energy from waste heat. In the presence of temperature gradients, charges in the thermoelectric material are diffused from the hotter to the colder side, inducing electrochemical potential inside the material. In wearable electronics, fiber-based thermoelectric generators (TEGs) are a unique energy harvesting device converting body heat into a reliable power source [168-170]. Since human body heat is a steady, plentiful, and convenient source of heat, it is meaningful and useful that TEG can harvest waste body heat. Kim et al. described a wearable TEG utilizing a combination of fabric and printed thermocouples that can be easily embedded in clothing to harvest low-temperature energy [169]. To prevent skin irritation, polymer-based fabric was used as a substrate and a conductive silver thread was used for electrical connection. When the TEG was integrated in a shirt, the temperature of the skin was maintained at $32{ }^{\circ} \mathrm{C}$ under cold $\left(5^{\circ} \mathrm{C}\right)$ or hot $\left(25^{\circ} \mathrm{C}\right)$ environments. Interestingly, the output power under cold environment was significantly higher at $\sim 147 \mathrm{nW}$ than that of the hot ambient environment, at $\sim 8.1 \mathrm{nW}$.

To investigate the suitability of thermoelectricity in wearable power generators, Du et al. reported a textile-based TEG featuring a long operating time, easy maintenance, and high reliability [168]. This TEG overcame the common problems of toxicity, poor processing ability, and impermeability by introducing a PEDOT:PSS conducting polymer. The inset of Figure 9e shows the morphology of polyester fabric coated with PEDOT:PSS, which had excellent flexibility in any shape [168]. The PEDOT:PSS-coated fabrics were connected using silver wires, as shown in Figure 9f. Using multiple strips of the fabricated device, the output voltage was improved to $4.3 \mathrm{mV}$ due to the Seebeck effect. Using a fabric thermoelectric generator containing 5 thermoelectric strip units, the maximum output of electrical power $\left(P_{\max }\right)$ was $12.29 \mathrm{nW}$ at a $\Delta T=75.2 \mathrm{~K}$, as shown in Figure 9f [168].

Despite the various advantages of TEGs, their limitations include a low energy conversion efficiency rate, slow technology progression, limited application possibilities, and the requirement of a constant heat source. The fabrication process is also complex because TEGs should be flexible and tightly adhere to the human body.

\subsection{Solar Cells on Textiles}

In the past decades, next-generation solar cells such as dye-sensitized solar cells (DSSC), organic solar cells (OSC), and perovskite solar cells (PSC) have attracted much attention due to their low cost and high efficiency [171-173]. These solar cells are based on light absorption using dye, organic, or perovskite materials that generate mobile electron-hole pairs [174]. The generated electrons and holes are separated and collected into cathodes and anodes, respectively. Recently, fiber-based solar cells have shown great potential for use in textile electronics and represent a new direction in solar energy harvesting since they can be woven into various types of flexible structures at low-cost. However, these devices would benefit from further study into the development of facile fabrication methods for large-scale production and realization of actual products as well as the feasibility of integration in cloth. Several researchers reporting wearable solar cells have primarily focused on inorganic, dye-sensitized, perovskite, and polymer-based solar cells with lightweight, flexible, and ease of manufacture $[38,99,175,176]$. 
Recent studies on dye-sensitized photovoltaic fibers have used primarily copper, steel wire, or polymer fibers coated with an indium tin oxide (ITO) electrode [177,178]. Cai et al. demonstrated a new method of fabricating $0.3 \mathrm{mM}$ cis-bis(isothiocyanato)bis(2,2'-bipyridyl-4,4'-dicarboxylato)ruthenium(II) bis-tetrabutylammonium (N719)-absorbed CNT fibers as a working electrode and CNT fibers coated with poly-vinylidene fluoride (PVDF) as a counter electrode for dye-sensitized photovoltaic application [178]. The fiber-based solar cell was integrated into textiles via conventional weaving techniques. The left side of Figure 10a shows a schematic illustration of the photovoltaic wire, while the middle image in Figure 10a shows an SEM image of the twisted CNT/N719 and CNT/PVDF fibers [178]. The open-circuit voltage and short-circuit current density of the fiber-based dye-sensitized solar cell were $0.69 \mathrm{~V}$ and $9.84 \mathrm{~mA} \cdot \mathrm{cm}^{-2}$, respectively, with a power conversion efficiency of $3.90 \%$, as shown in the right image in Figure 10a.

Zhang et al. demonstrated CdSe NWs and CNT yarn-based photovoltaics, with power conversion efficiency up to 3\% [179]. The left image in Figure 10b presents a schematic illustration of fiber-based CdSe-grafted $\mathrm{Ti}$ wire fabricated via chemical vapor deposition (CVD) with twisted CNT yarn. The SEM image in Figure 10b shows that the twisted CdSe-Ti wire and CNT fiber make smooth contact without the addition of electrolyte due to the flexibility of the yarn. The performance of CNT yarn and CdSe-Ti wire heterojunction with polysulfide electrodes was characterized by measuring the $\mathrm{J}-\mathrm{V}$ curve of the fiber cells. The open-circuit voltage $\left(V_{\mathrm{oc}}\right)$, short-circuit current density $\left(J_{\mathrm{sc}}\right)$, fill factor $(F F)$, and efficiency were $0.65 \mathrm{~V}, 8.25 \mathrm{~mA} \cdot \mathrm{cm}^{-2}, 55 \%$, and $2.9 \%$, respectively.

Recent successes in perovskite $\left(\mathrm{CH}_{3} \mathrm{NH}_{3} \mathrm{PbX}_{3}, \mathrm{X}=\mathrm{Cl}, \mathrm{Br}, \mathrm{I}\right)$ solar cells provide encouragement for flexible solar cells in wearable electronics [180,181]. Perovskite materials have many attractive properties including broad spectral absorption and high carrier mobility. The efficiency of thin film photovoltaic cells using perovskite materials have been recorded at up to $20 \%[182,183]$. Some attempts have been made to fabricate fiber-based perovskite solar cells for wearable electronics $[38,184]$; however, it is difficult to integrate the fibers into clothes due to the insufficient flexibility and low surface area of perovskite materials. To solve this issue, Li et al. described a CNT fiber-supported double-twisted perovskite solar cell featuring high stability where the perovskite nanocrystals on the CNT fiber sustain the interfacial adhesion under stress [38]. The left image in Figure 10d shows a schematic illustration of the CNT fiber-supported double-twisted perovskite solar cell using twisted $n$ - $\mathrm{TiO}_{2}$ added CNT, meso- $\mathrm{TiO}_{2}, \mathrm{CH}_{3} \mathrm{NH}_{3} \mathrm{PbI}_{3-x} \mathrm{Cl}_{x}, \mathrm{P} 3 \mathrm{HT} / \mathrm{SWNT}$, and an Ag nanowire network [38]. The P3HT/SWNT was used as a hole transport layer, and the Ag nanowire was added to increase the surface area between electrodes. The fabricated perovskite solar cell fiber can be seen in the middle of Figure 10d; the optimized maximum power conversion efficiency (PCE) was 3.03\%. Although the performance of the abovementioned textile-based photovoltaic harvesters are, some limitations such as mass production, high cost, and low energy conversion efficiency remained as obstacles to utilization in real fabrics. Further research into textile-based solar cells is needed for the realization of future wearable solar cells. 
a

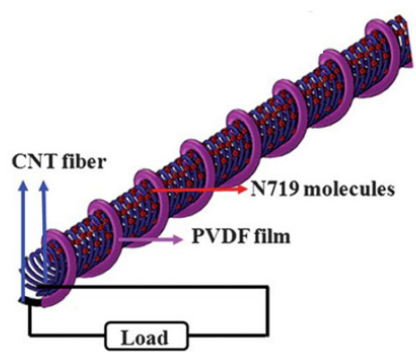

b

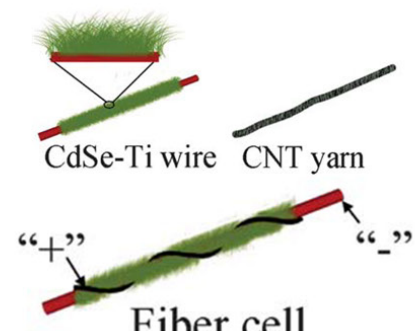

C

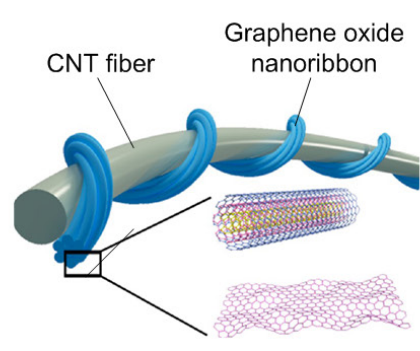

d

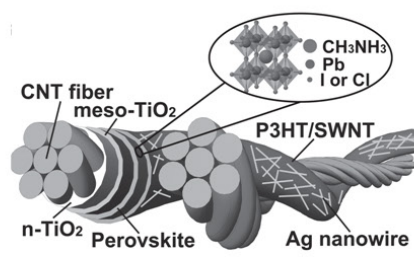

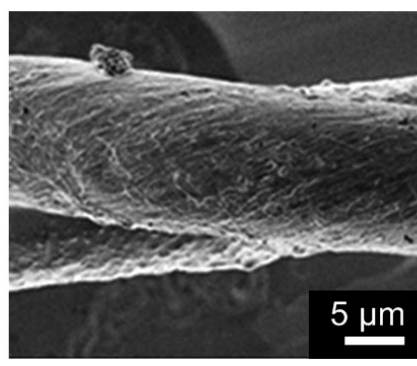
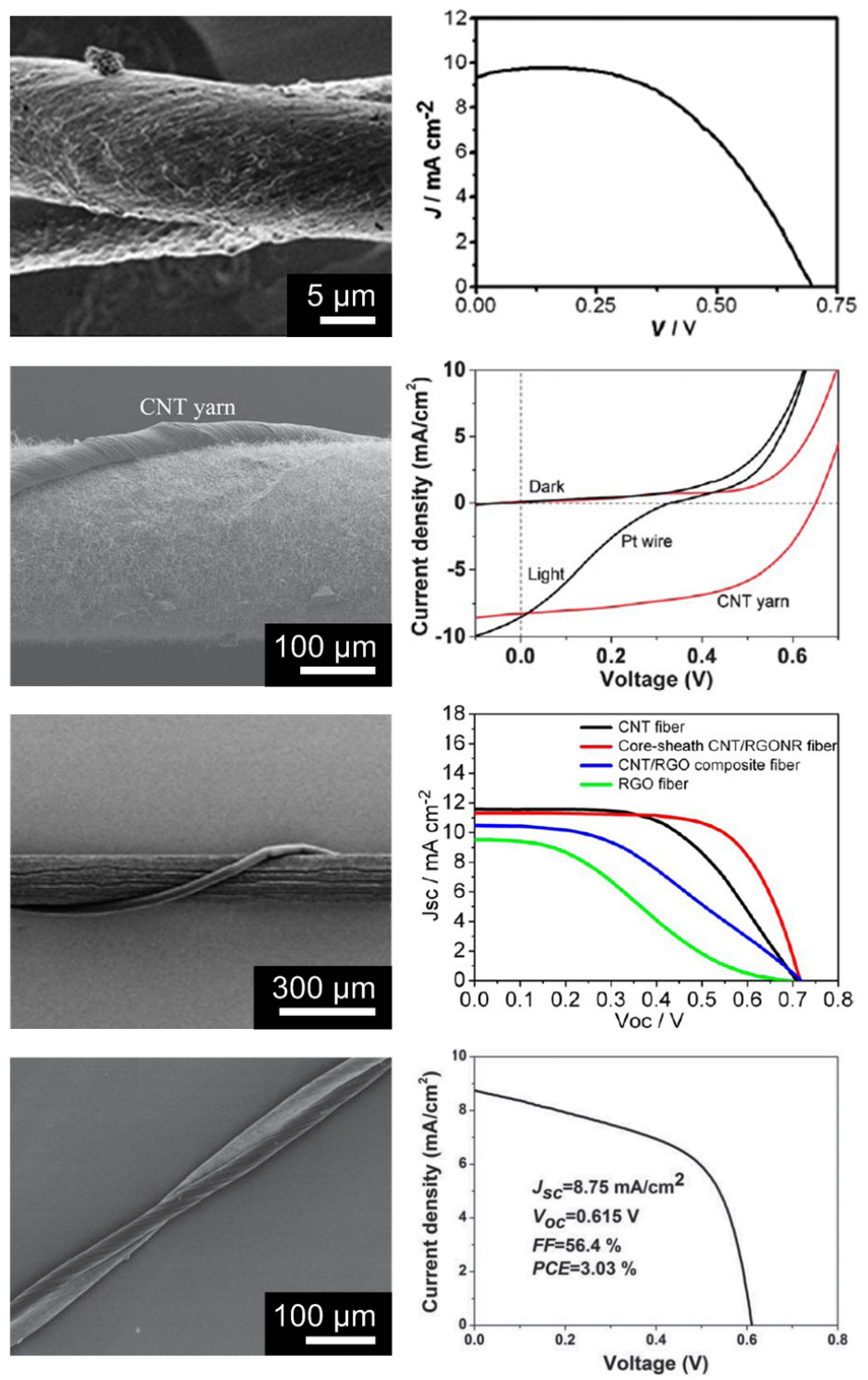

Figure 10. (a) Schematic (left) and SEM image (middle) of the twisted CNT/N719 working electrode and carbon nanotube/poly-vinylidene fluoride (CNT/PVDF) counter electrode. A typical density-voltage (J-V) curve (right) with improved performance after modification of the working electrode; (b) Schematic fabrication process (left) and SEM image (middle) of photo electrochemical cells with a primary electrode of Ti wire, light absorption layer of CdSe nanowire, and counter electrode of CNT. J-V curves under dark and light conditions of different fiber cells using a CNT yarn and Pt wire counter electrode; (c) Schematic (left) and SEM image (middle) of wire shaped dye-sensitized solar cells with twisted CNT fiber. Current density-voltage curves for a wire-shaped DSC (right); (d) Schematic diagram of double twisted solar cell supported by the CNT fiber and the chemical structure of the perovskite material (left). The SEM image shows twisted fibrous solar cells (middle). The current $\mathrm{J}-\mathrm{V}$ curve is shown for electrical performance (right). Reprinted from [38,99,175,178] with permissions by Royal Society of Chemistry, Copyright 2012, 2012 and by ACS Publications, Copyright 2013 and by John Wiley \& Sons, Copyright 2015. 


\subsection{Fabric-Based Supercapacitors}

Supercapacitors (SCs) have attracted significant attention as outstanding storage components due to their high power density, operational safety, long cycle life, and fast charge-discharge rates [185-187]. Depending on the mechanism of charge storage, SCs can be categorized into two types: the Electrical Double Layer Capacitor (EDLC) and pseudocapacitor. EDLCs are typically fabricated using two electrodes separated by a carbon-based electrolyte and an electrical double layer is formed between the electrodes and electrolyte based dielectric. Pseudocapacitors function based on reversible faradaic-type charging and discharging. The supercapacitor is made of conducting polymers and transition metal oxides, and the mechanism of energy storage depends on the redox reactions between materials. To integrate these supercapacitors into textiles, their components, including electrodes and current collectors, will have to be flexible.

Recently, Yang et al. demonstrated a pseudocapacitor-based supercapacitor with improved redox reaction and good reversibility [188]. To further improve the performance, one study introduced a hybrid architecture using $\mathrm{MnO}_{2}$-coated hydrogenated zinc oxide nanowires $(\mathrm{HZnO})$ grown on a flexible carbon cloth [189,190]. High electrochemical performance was exhibited by amorphous $\mathrm{ZnO}$-doped $\mathrm{MnO}_{2}$ core-shell nanocable (HZM) electrodes with a polyvinyl alcohol (PVA)/LiCl neutral electrolyte. Figure 11a shows a schematic illustration of the synthesis process of core-shell structures and an SEM image of HZM. The cyclic voltammetry (CV) measurement shown in Figure $11 \mathrm{~b}$ indicates that the $\mathrm{HZnO}$ electrode had a higher free carrier concentration and better electrical stability when compared to untreated $\mathrm{ZnO}$ and air-annealed $\mathrm{ZnO}$ electrodes which is attributed to the large surface area of the $\mathrm{HZnO}$ electrode.

This improvement was further explained by the insertion of hydrogen acting as a shallow donor for the neutral and electrically-inactive oxygen vacancies in $n$-type $\mathrm{ZnO}$. Figure $11 \mathrm{c}$ shows the combination of the energy harvesting module, dye-sensitized solar cells (DSSCs), and energy storage component that could illuminate a commercial blue LED from charged SCs when the solar source is off. Figure 11d shows a significant initial drop in the leakage current; this measurement stabilized after $4500 \mathrm{~s}$, indicating the presence of few impurities in the electrode and electrolyte. This research contributed to both the fundamental advancement of this technology as well as the advancement of potential of SCs applications.

Zhang et al. also developed a flexible energy fiber composed of titania nanotube-modified Ti wire and MWCNT that can store energy as well as harvest solar energy [191]. P3HT: 1-(3-methoxycarbonyl) propyl-1-phenyl [6,6] $\mathrm{C}_{61}$ (PCBM) and PEDOT:PSS with MWCNTs were used as photoactive materials and a $\mathrm{PVA} / \mathrm{H}_{3} \mathrm{PO}_{4}$ gel electrolyte was utilized for capacitor storage, as shown in Figure 11e. When the P3HT: PCBM heterojunction generates excitons and separate carriers (electrons and holes), the carriers are transported through MWCNTs and PEDOT:PSS, and then stored in the energy storage area. Figure $11 \mathrm{f}$ shows the energy fibers that were successfully woven into textiles. Figure $11 \mathrm{~g}$ describes the charge-discharge curves, which indicate a fast charging process. The maximum efficiency and energy storage capacity of the fibers are $\sim 1 \%$ and $\sim 65 \%$, respectively. These advances represent various new opportunities for the future of wearable electronics. 
a
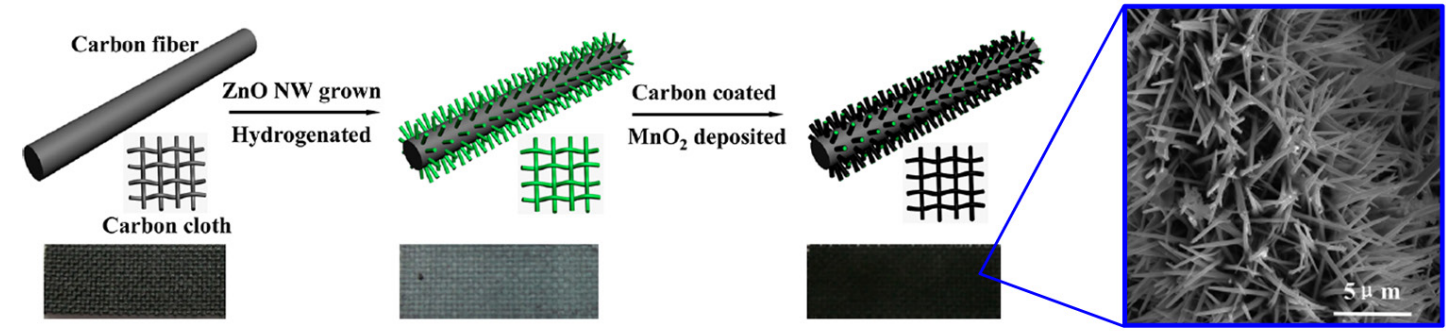

b

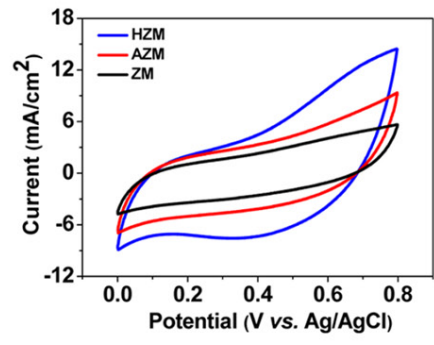

C

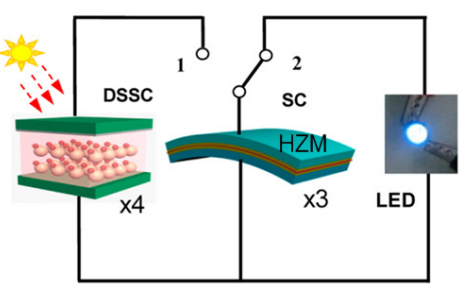

d

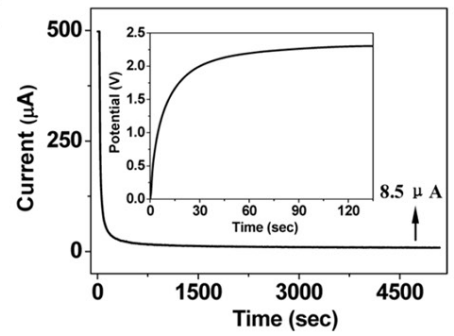

e

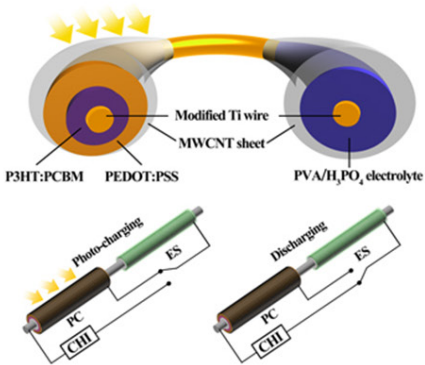

f

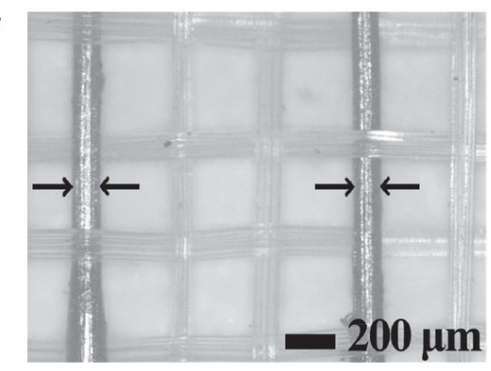

g

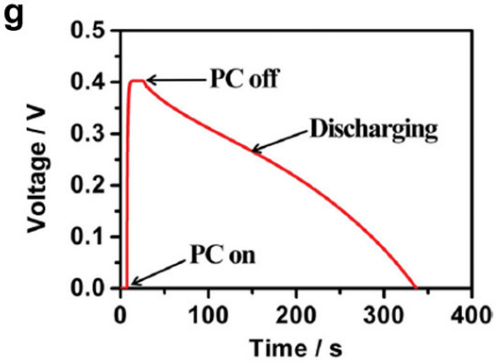

Figure 11. (a) Schematic fabrication process and SEM image of a hydrogenated single crystal $\mathrm{ZnO}(\mathrm{HZM})$ and amorphous $\mathrm{ZnO}$-doped $\mathrm{MnO}_{2}$ core-shell electrodes; (b) Current-potential characterization with different electrodes with scan rates of $100 \mathrm{mV} / \mathrm{s}$; (c) Design of a stand-alone self-powered system consisting of dye-sensitized solar cells (DSSCs), SCs, and LEDs; (d) Leakage current characteristics of three SCs in series and voltage profile (inset) charged by four DSSCs in series; (e) Schematic illustration and circuit connection mechanism in the process of charging and discharging of photovoltaic conversion (PC) and energy storage (ES) with titania nanotube-modified Ti wire and aligned MWCNT sheet as two electrodes; (f) Photography of energy fibers woven with each other to form flexible textiles; (g) Charging-discharging curve with a current of $0.1 \mu \mathrm{A}$ during the discharging process with the ES part. Reproduced from $[188,191]$ with permissions by ACS Publications, Copyright 2013 and by John Wiley \& Sons, Copyright 2014.

\section{Current Limitations of Wearable E-textiles}

Aforementioned discussion on the wearable E-textiles presents them as a good futuristic candidate in daily life of human outfits. However, for the true realization of wearable E-textiles, some basic issues must be addressed.

One of the main limitations of wearable E-textiles which require more concern is toxicity due to hazards materials used in electronic components. If, we integrate the electronic components in the wearable textiles they must be safe and non-toxic. Electronic components contain toxic material for example batteries have toxic and liquid electrolyte material like Li-ion batteries and tetraethylammonium tetrafluoroborate in acetonitrile [186,192]. Therefore, garments integrated with these electronic 
components are not suitable to wear because they will be in directly contact with skin. To resolve this issue some reports are available to use a non-toxic material. Jost et al. have fabricated flexible and durable textile electrodes for supercapacitors by using non-toxic electrolyte material (sodium and lithium sulfate) [193]. The as prepared fabric electrodes have shown high areal capacitance but the problem with these fabric electrodes is the requirement of an integrated device to seal the liquid electrolyte to avoid its leakage. Further, a non-toxic electrolyte based wearable supercapacitor has been suggested by pasta et al. in their well-arranged study [194]. They have reported a simple fabrication technique for supercapacitor showing high specific capacitance and cycling stability. But the drawback of as prepared supercapacitor is the hydrogen evolution overvoltage prevents the operative voltage range as similarly reported by Prosini et al. [195]. Several other reports are also available on non-toxic electrolyte materials. However, further improvements are required in order to use these components in wearable textiles and toxicity issue should be carefully monitored before employ them in wearable fabrics.

Other drawback of these wearable E-textiles is related to their multiple uses, i.e., washability and durability. To the best of our knowledge, there is no study on multiple washable textiles integrated with electronic components. In general, multiple washing and special care is required to worn these garments in daily life. Also, the long term usage of these wearable E-textiles is again a matter of concern. It is required to know that the repairing as well as exchanging of electronic device is possible during their long term use by wearer. The other challenge for researchers is to focus on the packaging of electronic components and device performance for their usage over the longer time. Due to crack and poor bending properties of fiber-based electronics, failure of packaging is observed [196]. These wearable electronic fabrics must hold their sensing, actuating and responding properties in qualitative way during their everyday wear and off-course maintain comfort fit to human body. This can be achieved by replacing hard printed circuit board to flexible electronics.

For the practically implementation of these wearable fabrics the mass production is required and for this an interdisciplinary work must be involved between electronic as well as textile peoples. But to the best of knowledge there is a lack of combination of electronics and textiles industries. Thus, for future developments of E-textiles it is required that the experts of these two firms must work together. Other issues include the biocompatibility of these textiles, development of sophisticated multi-functionalities, stable performance of devices and light weight fabrics for future applications. Thus, any realistic commercial implementation can be achieved after addressing all pointed issues.

\section{Conclusions and Perspectives}

In this review article, a brief overview of textile electronics is presented based on electronic components, in which the various types of conductive fibers and fabrication techniques are summarized using different materials such as polymers, CNTs, graphene, and metal nanowires. Fiber-based electronic components (transistors, LEDs, and sensors) have also been described. Furthermore, textile-based energy harvesting and storage devices were explained for energy applications in textile electronics. Although considerable performance in textile-based electronic devices has already been achieved, further efforts to improve performance are necessary. A significant body of theoretical and experimental research has been carried out to understand the mechanism and 
characteristics of E-textiles in wearable electronics. To commercialize textile-based devices in wearable electronics, some important issues will have to be addressed, including mass production, integration into clothes, non-toxic technology, and long-term usage. If the E-textiles can overcome the aforementioned issues, a new era in wearable electronics will begin.

\section{Acknowledgments}

This work was supported by the LG Yonam Foundation. We are thankful to the LG group for the support based on Academic Support Programs of LG Yonam Foundation.

\section{Author Contributions}

All authors discussed the contents of the review manuscript. V.K. wrote the text of the manuscript. S.L., J.H. and J.L. made the Figures for paper. C.M. also contributed to write the manuscript and revised by V.K. and S.L. Modifications and the proof reading of the manuscript has been done by J.S., S.L., J.H., S.L. and V.K. The manuscript is prepared under the supervision of T.L.

\section{Conflicts of Interest}

The authors declare no conflict of interest.

\section{References}

1. Csapó, Á.; Wersényi, G.; Nagy, H.; Stockman, T. A survey of assistive technologies and applications for blind users on mobile platforms: A review and foundation for research. J. Multimodal User Interfaces 2015, doi:10.1007/s12193-015-0182-7.

2. Lewis, Z.H.; Lyons, E. J.; Jarvis, J.M.; Baillargeon, J. Using an electronic activity monitor system as an intervention modality: A systematic review. BMC Public Health 2015, 15, 585-600.

3. Vanveerdeghem, P.; Van Torre, P.; Thielens, A.; Knockaert, J.; Joseph, W.; Rogier, H. Compact personal distributed wearable exposimeter. IEEE Sens. J. 2015, 15, 4393-4401.

4. Yun, J.Y.; Hong, W.G.; Choi, N.-J.; Kim, H.B.; Jun, Y.; Lee, H.-K. Ultrasensitive and highly selective graphene-based single yarn for use in wearable gas sensor. Sci. Rep. 2015, 5, 10904-10910.

5. Bai, P.F.; Hayes, R.A.; Jin, M.; Shui, L.; Yi, Z.C.; Wang, L.; Zhang, X.; Zhou, G. Review of paper-like display technologies (invited review). Prog. Electromagn. Res. 2014, 147, 95-116.

6. Patel, S.; Park, H.; Bonato, P.; Chan, L.; Rodgers, M. A review of wearable sensors and systems with application in rehabilitation. J. Neuroeng. Rehabil. 2012, 9, 1-17.

7. Bell, A.G. Phone and Other Inventions. Available online: http://www.carnetdevol.org/Bell/ Phone.html (accessed on 3 August 2015).

8. Tropp, H. Computer report VII: The effervescent years: A retrospective: Behind the computer revolution lay the vision and perseverance of a handful of pioneers committed to open information exchange. IEEE Spectr. 1974, 11, 70-79.

9. Goldstine, H.H.; Goldstine, A. The electronic numerical integrator and computer (ENIAC). IEEE Ann. Hist. Comput. 1996, 18, 10-16. 
10. Myslewski, R. File:Ibm pcjr with display.jpg. Available online: https://commons.wikimedia.org/ wiki/File:Ibm_pcjr_with_display.jpg (accessed on 14 July 2015).

11. Gilbert, D. Mobile Phone Celebrates 40th Birthday. Available online: http://www.ibtimes.co.uk/ mobile-phone-40-years-motorola-dynatac-history-453057 (accessed on 3 August 2015).

12. Steven, S. Epson-hx-20. Available online: https://upload.wikimedia.org/wikipedia/commons/8/ 8d/Epson-hx-20.jpg (accessed on 14 July 2015).

13. Mann, S. Smart clothing: The wearable computer and wearcam. Pers. Technol. 1997, 1, 21-27.

14. Ritchie, R. History of iPhone: Apple reinvents the phone. Available online: http://www.imore.com/ history-iphone-2g (accessed on 3 August 2015).

15. Ackerman, E. Google gets in your face. IEEE Spectr. 2013, 50, 26-29.

16. Apple. Apple Watch. Available online: http://www.apple.com/kr/watch/gallery/ (accessed on 3 August 2015).

17. Popat, K.A.; Sharma, P. Wearable computer applications a future perspective. Int. J. Eng. Innov. Technol. 2013, 3, 213-217.

18. Someya Group Organic Transistor Lab Press Kits. Available online: http:/www.ntech.t.utokyo.ac.jp/en/press/press_for_media/index.html (accessed on 3 August 2015).

19. Caron, N. Meet the Rest of the Cast for Fox's Minority Report TV series. Available online: $\mathrm{http} / / / \mathrm{www} \cdot$ blastr.com/2015-3-3/meet-rest-cast-foxs-minority-report-tv-series (accessed on 3 August 2015).

20. Lee, J.; Kwon, H.; Seo, J.; Shin, S.; Koo, J.H.; Pang, C.; Son, S.; Kim, J.H.; Jang, Y.H.; Kim, D.E.; Lee, T. Conductive fiber-based ultrasensitive textile pressure sensor for wearable electronics. Adv. Mater. 2015, 27, 2433-2439.

21. Seesaard, T.; Lorwongtragool, P.; Kerdcharoen, T. Development of fabric-based chemical gas sensors for use as wearable electronic noses. Sensors 2015, 15, 1885-1902.

22. Skrzetuska, E.; Puchalski, M.; Krucińska, I. Chemically driven printed textile sensors based on graphene and carbon nanotubes. Sensors 2014, 14, 16816-16828.

23. Lanata, A.; Valenza, G.; Nardelli, M.; Gentili, C.; Scilingo, E.P. Complexity index from a personalized wearable monitoring system for assessing remission in mental health. IEEE J. Biomed. Health Inform. 2015, 19, 132-139.

24. Zheng, Y.-L.; Ding, X.-R.; Poon, C.C.Y.; Lo, B.P.L.; Zhang, H.; Zhou, X.-L.; Yang, G.-Z.; Zhao, N.; Zhang, Y.-T. Unobtrusive sensing and wearable devices for health informatics. IEEE Trans. Biomed. Eng. 2014, 61, 1538-1554.

25. Zheng, N.; Wu, Z.; Lin, M.; Yang, L.T. Enhancing battery efficiency for pervasive health-monitoring systems based on electronic textiles. IEEE Trans. Inf. Technol. Biomed. 2010, 14, 350-359.

26. Paradiso, R.; Loriga, G.; Taccini, N. A wearable health care system based on knitted integrated sensors. IEEE Trans. Inf. Technol. Biomed. 2005, 9, 337-344.

27. Quinlan, M.; Mayhew, C. The effects of outsourcing on occupational health and safety: A comparative study of factory-based workers and outworkers in the Australian clothing industry. Int. J. Health Serv. 1999, 29, 83-107.

28. Rofouei, M.; Potkonjak, M.; Sarrafzadeh, M. Energy efficient collaborative sensing-based design: Soft keyboard case study. IEEE Trans. Hum. Mach. Syst. 2014, 44, 115-124. 
29. Yoo, H.-J. Your heart on your sleeve: Advances in textile-based electronics are weaving computers right into the clothes we wear. IEEE Solid State Circuits Mag. 2013, 5, 59-70.

30. Li, W.; Zhu, L.; Gu, J.; Liu, H. Microwave absorption properties of fabric coated absorbing material using modified carbonyl iron power. Compos. Part B Eng. 2011, 42, 626-630.

31. Moro, R.; Agneessens, S.; Rogier, H.; Dierck, A.; Bozzi, M. Textile microwave components in substrate integrated waveguide technology. IEEE Trans. Microw. Theory Tech. 2015, 63, $422-432$.

32. Castano, L.M.; Flatau, A.B. Smart fabric sensors and E-textile technologies: A review. Smart Mater. Struct. 2014, 23, 053001-053027.

33. Stoppa, M.; Chiolerio, A. Wearable electronics and smart textiles: A critical review. Sensors 2014, 14, 11957-11992.

34. Zięba, J.; Frydrysiak, M. Textronics-electrical and electronic textiles. Sensors for breathing frequency measurement. Fibres Text. East. Eur. 2006, 14, 43-48.

35. Sun, H.; You, X.; Yang, Z.; Deng, J.; Peng, H. Winding ultrathin, transparent, and electrically conductive carbon nanotube sheets into high-performance fiber-shaped dye-sensitized solar cells. J. Mater. Chem. A 2013, 1, 12422-12425.

36. Weintraub, B.; Wei, Y.; Wang, Z.L. Optical fiber/nanowire hybrid structures for efficient three-dimensional dye-sensitized solar cells. Angew. Chem. Int. Ed. 2009, 48, 8981-8985.

37. Liu, D.; Zhao, M.; Li, Y.; Bian, Z.; Zhang, L.; Shang, Y.; Xia, X.; Zhang, S.; Yun, D.; Liu, Z.; Cao, A.; Huang, C. Solid-state, polymer-based fiber solar cells with carbon nanotube electrodes. ACS Nano 2012, 6, 11027-11034.

38. Li, R.; Xiang, X.; Tong, X.; Zou, J.; Li, Q. Wearable double-twisted fibrous perovskite solar cell. Adv. Mater. 2015, 27, 3831-3835.

39. Lee, J.B.; Subramanian, V. Weave patterned organic transistors on fiber for E-textiles. IEEE Trans. Electron Devices 2005, 52, 269-275.

40. Tao, X.; Koncar, V.; Dufour, C. Geometry pattern for the wire organic electrochemical textile transistor. J. Electrochem. Soc. 2011, 158, H572-H577.

41. Kylberg, W.; de Castro, F.A.; Chabrecek, P.; Sonderegger, U.; Chu, B.T.-T.; Nüesch, F.; Hany, R. Woven electrodes for flexible organic photovoltaic cells. Adv. Mater. 2011, 23, 1015-1019.

42. Zhang, Z.; Guo, K.; Li, Y.; Li, X.; Guan, G.; Li, H.; Luo, Y.; Zhao, F.; Zhang, Q.; Wei, B.; Pei, Q.; Peng, H. A colour-tunable, weavable fibre-shaped polymer light-emitting electrochemical cell. Nat. Photonics 2015, 9, 233-238.

43. Vohra, V.; Giovanella, U.; Tubino, R.; Murata, H.; Botta, C. Electroluminescence from conjugated polymer electrospun nanofibers in solution processable organic light-emitting diodes. ACS Nano 2011, 5, 5572-5578.

44. Bedeloglu, A.; Demir, A.; Bozkurt, Y.; Sariciftci, N.S. A flexible textile structure based on polymeric photovoltaics using transparent cathode. Synth. Met. 2009, 159, 2043-2048.

45. Jost, K.; Dion, G.; Gogotsi, Y. Textile energy storage in perspective. J. Mater. Chem. A 2014, 2, 10776-10787.

46. Wang, Z.L. Towards self-powered nanosystems: From nanogenerators to nanopiezotronics. Adv. Funct. Mater. 2008, 18, 3553-3567. 
47. Das, T.K.; Prusty, S. Review on conducting polymers and their applications. Polym. Plast. Technol. Eng. 2012, 51, 1487-1500.

48. Wegner, G. Polymers with metal-like conductivity-A review of their synthesis, structure and properties. Angew. Chem. Int. Ed. Engl. 1981, 20, 361-381.

49. Patil, A.O.; Heeger, A.J.; Wudl, F. Optical properties of conducting polymers. Chem. Rev. 1988, $88,183-200$.

50. Gerard, M.; Chaubey, A.; Malhotra, B.D. Application of conducting polymers to biosensors. Biosens. Bioelectron. 2002, 17, 345-359.

51. Janata, J.; Josowicz, M. Conducting polymers in electronic chemical sensors. Nat. Mater. 2003, $2,19-24$.

52. Svirskis, D.; Travas-Sejdic, J.; Rodgers, A.; Garg, S. Electrochemically controlled drug delivery based on intrinsically conducting polymers. J. Controlled Release 2010, 146, 6-15.

53. Pernaut, J.-M.; Reynolds, J.R. Use of conducting electroactive polymers for drug delivery and sensing of bioactive molecules. A redox chemistry approach. J. Phys. Chem. B 2000, 104, 4080-4090.

54. Tallman, D.E.; Spinks, G.; Dominis, A.; Wallace, G.G. Electroactive conducting polymers for corrosion control. J. Solid State Electrochem. 2001, 6, 73-84.

55. Hohnholz, D.; Okuzaki, H.; MacDiarmid, A.G. Plastic electronic devices through line patterning of conducting polymers. Adv. Funct. Mater. 2005, 15, 51-56.

56. Green, R.A.; Lovell, N.H.; Wallace, G.G.; Poole-Warren, L.A. Conducting polymers for neural interfaces: Challenges in developing an effective long-term implant. Biomaterials 2008, 29, 3393-3399.

57. Olmedo, L.; Hourquebie, P.; Jousse, F. Microwave absorbing materials based on conducting polymers. Adv. Mater. 1993, 5, 373-377.

58. Malinauskas, A. Electrocatalysis at conducting polymers. Synth. Met. 1999, 107, 75-83.

59. Kingsborough, R.P.; Swager, T.M. Electrocatalytic conducting polymers: Oxygen reduction by a polythiophene-cobalt salen hybrid. Chem. Mater. 2000, 12, 872-874.

60. Shirakawa, H.; Louis, E.J.; MacDiarmid, A.G.; Chiang, C.K.; Heeger, A.J. Synthesis of electrically conducting organic polymers: Halogen derivatives of polyacetylene, $(\mathrm{CH})_{x} . J$. Chem. Soc. Chem. Commun. 1977, 578-580.

61. Schreuder-Gibson, H.L.; Truong, Q.; Walker, J.E.; Owens, J.R.; Wander, J.D.; Jones, W.E. Chemical and biological protection and detection in fabrics for protective clothing. MRS Bull. 2003, 28, 574-578.

62. Cochrane, C.; Koncar, V.; Lewandowski, M.; Dufour, C. Design and development of a flexible strain sensor for textile structures based on a conductive polymer composite. Sensors 2007, 7, 473-492.

63. De Rossi, D.; Carpi, F.; Lorussi, F.; Mazzoldi, A.; Paradiso, R.; Scilingo, E.P.; Tognetti, A. Electroactive fabrics and wearable biomonitoring devices. AUTEX Res. J. 2003, 3, 180-185.

64. Smith, D. Smart clothes and wearable technology. AI Soc. 2007, 22, 1-3.

65. Park, S.; Jayaraman, S. Smart textiles: Wearable electronic systems. MRS Bull. 2003, 28, $585-591$. 
66. Kim, M.S.; Kim, H.K.; Byun, S.W.; Jeong, S.H.; Hong, Y.K.; Joo, J.S.; Song, K.T.; Kim, J.K.; Lee, C.J.; Lee, J.Y. PET fabric/polypyrrole composite with high electrical conductivity for EMI shielding. Synth. Met. 2002, 126, 233-239.

67. Varesano, A.; Dall'Acqua, L.; Tonin, C. A study on the electrical conductivity decay of polypyrrole coated wool textiles. Polym. Degrad. Stab. 2005, 89, 125-132.

68. Ding, Y.; Invernale, M.A.; Sotzing, G.A. Conductivity trends of PEDOT-PSS impregnated fabric and the effect of conductivity on electrochromic textile. ACS Appl. Mater. Interfaces 2010, 2, 1588-1593.

69. Gospodinova, N.; Terlemezyan, L. Conducting polymers prepared by oxidative polymerization: Polyaniline. Prog. Polym. Sci. 1998, 23, 1443-1484.

70. Jianming, J.; Wei, P.; Shenglin, Y.; Guang, L. Electrically conductive PANI-DBSA/Co-PAN composite fibers prepared by wet spinning. Synth. Met. 2005, 149, 181-186.

71. Dallas, P.; Niarchos, D.; Vrbanic, D.; Boukos, N.; Pejovnik, S.; Trapalis, C.; Petridis, D. Interfacial polymerization of pyrrole and in situ synthesis of polypyrrole/silver nanocomposites. Polymer 2007, 48, 2007-2013.

72. Müller, D.; Rambo, C.R.; Recouvreux, D.O.S.; Porto, L.M.; Barra, G.M.O. Chemical in situ polymerization of polypyrrole on bacterial cellulose nanofibers. Synth. Met. 2011, 161, 106-111.

73. Xu, R.; Wei, J.; Guo, F.; Cui, X.; Zhang, T.; Zhu, H.; Wang, K.; Wu, D. Highly conductive, twistable and bendable polypyrrole-carbon nanotube fiber for efficient supercapacitor electrodes. RSC Adv. 2015, 5, 22015-22021.

74. Zhang, Y.; Rutledge, G.C. Electrical conductivity of electrospun polyaniline and polyaniline-blend fibers and mats. Macromolecules 2012, 45, 4238-4246.

75. Balint, R.; Cassidy, N.J.; Cartmell, S.H. Conductive polymers: Towards a smart biomaterial for tissue engineering. Acta Biomater. 2014, 10, 2341-2353.

76. Moulé, A.J.; Jung, M.-C.; Rochester, C.W.; Tress, W.; LaGrange, D.; Jacobs, I.E.; Li, J.; Mauger, S.A.; Rail, M.D.; Lin, O.; Bilsky, D.J.; Qi, Y.; Stroeve, P.; Berben, L.A.; Riede, M. Mixed interlayers at the interface between PEDOT:PSS and conjugated polymers provide charge transport control. J. Mater. Chem. C 2015, 3, 2664-2676.

77. Pomfret, S.J.; Adams, P.N.; Comfort, N.P.; Monkman, A.P. Electrical and mechanical properties of polyaniline fibres produced by a one-step wet spinning process. Polymer 2000, 41, 2265-2269.

78. Huang, K.; Wan, M.; Long, Y.; Chen, Z.; Wei, Y. Multi-functional polypyrrole nanofibers via a functional dopant-introduced process. Synth. Met. 2005, 155, 495-500.

79. Wallace, G.G.; Campbell, T.E.; Innis, P.C. Putting function into fashion: Organic conducting polymer fibres and textiles. Fibers Polym. 2007, 8, 135-142.

80. Chacko, A.P.; Hardaker, S.S.; Gregory, R.V.; Samuels, R.J. Viscoelastic characterization of concentrated polyaniline solutions: New insights into conductive polymer processing. Synth. Met. 1997, 84, 41-44.

81. Mottaghitalab, V.; Spinks, G.M.; Wallace, G.G. The development and characterisation of polyaniline-Single walled carbon nanotube composite fibres using 2-acrylamido-2 methyl-1propane sulfonic acid (AMPSA) through one step wet spinning process. Polymer 2006, 47, 4996-5002. 
82. Takahashi, T.; Ishihara, M.; Okuzaki, H. Poly(3,4-ethylenedioxythiophene)/poly(4-styrenesulfonate) microfibers. Synth. Met. 2005, 152, 73-76.

83. Yun, Y.J.; Hong, W.G.; Kim, W.-J.; Jun, Y.; Kim, B.H. A novel method for applying reduced graphene oxide directly to electronic textiles from yarns to fabrics. Adv. Mater. 2013, 25, 5701-5705.

84. Meng, Y.; Zhao, Y.; Hu, C.; Cheng, H.; Hu, Y.; Zhang, Z.; Shi, G.; Qu, L. All-graphene core-sheath microfibers for all-solid-state, stretchable fibriform supercapacitors and wearable electronic textiles. Adv. Mater. 2013, 25, 2326-2331.

85. Jang, E.Y.; Kang, T.J.; Im, H.; Baek, S.J.; Kim, S.; Jeong, D.H.; Park, Y.W.; Kim, Y.H. Macroscopic single-walled-carbon-nanotube fiber self-assembled by dip-coating method. Adv. Mater. 2009, 21, 4357-4361.

86. Chen, T.; Cai, Z.; Yang, Z.; Li, L.; Sun, X.; Huang, T.; Yu, A.; Kia, H.G.; Peng, H. Nitrogen-doped carbon nanotube composite fiber with a core-sheath structure for novel electrodes. Adv. Mater. 2011, 23, 4620-4625.

87. Hu, L.; Pasta, M.; Mantia, F.L.; Cui, L.; Jeong, S.; Deshazer, H.D.; Choi, J.W.; Han, S.M.; Cui, Y. Stretchable, porous, and conductive energy textiles. Nano Lett. 2010, 10, 708-714.

88. Lee, H.M.; Choi, S.-Y.; Jung, A.; Ko, S.H. Highly conductive aluminum textile and paper for flexible and wearable electronics. Angew. Chem. Int. Ed. 2013, 52, 7718-7723.

89. Park, M.; Im, J.; Shin, M.; Min, Y.; Park, J.; Cho, H.; Park, S.; Shim, M.-B.; Jeon, S.; Chung, D.-Y.; et al. Highly stretchable electric circuits from a composite material of silver nanoparticles and elastomeric fibres. Nat. Nanotechnol. 2012, 7, 803-809.

90. Lee, S.; Shin, S.; Lee, S.; Seo, J.; Lee, J.; Son, S.; Cho, H.J.; Algadi, H.; Al-Sayari, S.; Kim, D.E.; Lee, T. Ag nanowire reinforced highly stretchable conductive fibers for wearable electronics. Adv. Funct. Mater. 2015, 25, 3114-3121.

91. Wu, A.S.; Nie, X.; Hudspeth, M.C.; Chen, W.W.; Chou, T.-W.; Lashmore, D.S.; Schauer, M.W.; Tolle, E.; Rioux, J. Strain rate-dependent tensile properties and dynamic electromechanical response of carbon nanotube fibers. Carbon 2012, 50, 3876-3881.

92. Koziol, K.; Vilatela, J.; Moisala, A.; Motta, M.; Cunniff, P.; Sennett, M.; Windle, A. High-performance carbon nanotube fiber. Science 2007, 318, 1892-1895.

93. Chen, H.; Müller, M.B.; Gilmore, K.J.; Wallace, G.G.; Li, D. Mechanically strong, electrically conductive, and biocompatible graphene paper. Adv. Mater. 2008, 20, 3557-3561.

94. Baughman, R.H.; Zakhidov, A.A.; de Heer, W.A. Carbon nanotubes-The route toward applications. Science 2002, 297, 787-792.

95. Kaushik, V.; Sharma, H.; Girdhar, P.; Shukla, A.K.; Vankar, V.D. Structural modification and enhanced electron emission from multiwalled carbon nanotubes grown on $\mathrm{Ag} / \mathrm{Fe}$ catalysts coated Si-substrates. Mater. Chem. Phys. 2011, 130, 986-992.

96. Cao, A.; Dickrell, P.L.; Sawyer, W.G.; Ghasemi-Nejhad, M.N.; Ajayan, P.M. Super-compressible foamlike carbon nanotube films. Science 2005, 310, 1307-1310.

97. Jakubinek, M.B.; Johnson, M.B.; White, M.A.; Jayasinghe, C.; Li, G.; Cho, W.; Schulz, M.J.; Shanov, V. Thermal and electrical conductivity of array-spun multi-walled carbon nanotube yarns. Carbon 2012, 50, 244-248. 
98. Ericson, L.M.; Fan, H.; Peng, H.; Davis, V.A.; Zhou, W.; Sulpizio, J.; Wang, Y.; Booker, R.; Vavro, J.; Guthy, C.; et al. Macroscopic, neat, single-walled carbon nanotube fibers. Science 2004, 305, 1447-1450.

99. Zhang, L.; Shi, E.; Ji, C.; Li, Z.; Li, P.; Shang, Y.; Li, Y.; Wei, J.; Wang, K.; Zhu, H.; et al. Fiber and fabric solar cells by directly weaving carbon nanotube yarns with $\mathrm{CdSe}$ nanowire-based electrodes. Nanoscale 2012, 4, 4954-4959.

100. Davis, V.A.; Parra-Vasquez, A.N.G.; Green, M.J.; Rai, P.K.; Behabtu, N.; Prieto, V.; Booker, R.D.; Schmidt, J.; Kesselman, E.; Zhou, W.; et al. True solutions of single-walled carbon nanotubes for assembly into macroscopic materials. Nat. Nanotechnol. 2009, 4, 830-834.

101. Vigolo, B.; Pénicaud, A.; Coulon, C.; Sauder, C.; Pailler, R.; Journet, C.; Bernier, P.; Poulin, P. Macroscopic fibers and ribbons of oriented carbon nanotubes. Science 2000, 290, 1331-1334.

102. Shim, B.S.; Chen, W.; Doty, C.; Xu, C.; Kotov, N. A. Smart electronic yarns and wearable fabrics for human biomonitoring made by carbon nanotube coating with polyelectrolytes. Nano Lett. 2008, 8, 4151-4157.

103. Zhang, S.; Koziol, K.K.K.; Kinloch, I.A.; Windle, A.H. Macroscopic fibers of well-aligned carbon nanotubes by wet spinning. Small 2008, 4, 1217-1222.

104. Zhao, Y.; Wei, J.; Vajtai, R.; Ajayan, P. M.; Barrera, E. V. Iodine doped carbon nanotube cables exceeding specific electrical conductivity of metals. Sci. Rep. 2011, 1, 83-87.

105. Jiang, K.; Li, Q.; Fan, S. Nanotechnology: Spinning continuous carbon nanotube yarns. Nature 2002, 419, 801-801.

106. Xu, Z.; Zhang, Y.; Li, P.; Gao, C. Strong, conductive, lightweight, neat graphene aerogel fibers with aligned pores. ACS Nano 2012, 6, 7103-7113.

107. Scholz, J.; Nocke, G.; Hollstein, F.; Weissbach, A. Investigations on fabrics coated with precious metals using the magnetron sputter technique with regard to their anti-microbial properties. Surf. Coat. Technol. 2005, 192, 252-256.

108. Hegemann, D.; Amberg, M.; Ritter, A.; Heuberger, M. Recent developments in Ag metallised textiles using plasma sputtering. Mater. Technol. 2009, 24, 41-45.

109. Little, B.K.; Li, Y.; Cammarata, V.; Broughton, R.; Mills, G. Metallization of kevlar fibers with gold. ACS Appl. Mater. Interfaces 2011, 3, 1965-1973.

110. Zhang, Z.; Dai, S.; Blom, D.A.; Shen, J. Synthesis of ordered metallic nanowires inside ordered mesoporous materials through electroless deposition. Chem. Mater. 2002, 14, 965-968.

111. Zrnic, D.; Swatik, D.S. On the resistivity and surface tension of the eutectic alloy of gallium and indium. J. Common Met. 1969, 18, 67-68.

112. Zhu, S.; So, J.-H.; Mays, R.; Desai, S.; Barnes, W.R.; Pourdeyhimi, B.; Dickey, M.D. Ultrastretchable fibers with metallic conductivity using a liquid metal alloy core. Adv. Funct. Mater. 2013, 23, 2308-2314.

113. Atwa, Y.; Maheshwari, N.; Goldthorpe, I.A. Silver nanowire coated threads for electrically conductive textiles. J. Mater. Chem. C 2015, 3, 3908-3912.

114. Horowitz, G. Organic field-effect transistors. Adv. Mater. 1998, 10, 365-377.

115. Muccini, M.A bright future for organic field-effect transistors. Nat. Mater. 2006, 5, 605-613.

116. Małachowski, M.J.; Żmija, J. Organic field-effect transistors. Opto-Electron. Rev. 2010, 18, 121-136. 
117. Sun, Y.; Liu, Y.; Zhu, D. Advances in organic field-effect transistors. J. Mater. Chem. 2005, 15, 53-65.

118. Lee, J.B.; Subramanian, V. Organic Transistors on Fiber: A First Step Towards Electronic Textiles. In Proceedings of IEEE International Electron Devices Meeting (IEDM '03), Technical Digest, Washington, DC, USA, 8-10 December 2003; pp. 8.3.1-8.3.4.

119. Garnier, F.; Horowitz, G.; Peng, X.; Fichou, D. An all-organic "soft" thin film transistor with very high carrier mobility. Adv. Mater. 1990, 2, 592-594.

120. Tsumura, A.; Koezuka, H.; Ando, T. Macromolecular electronic device: Field-effect transistor with a polythiophene thin film. Appl. Phys. Lett. 1986, 49, 1210-1212.

121. De Rossi, D. Electronic textiles: A logical step. Nat. Mater. 2007, 6, 328-329.

122. Maccioni, M.; Orgiu, E.; Cosseddu, P.; Locci, S.; Bonfiglio, A. Towards the textile transistor: Assembly and characterization of an organic field effect transistor with a cylindrical geometry. Appl. Phys. Lett. 2006, 89, 143515-143517.

123. Hamedi, M.; Forchheimer, R.; Inganäs, O. Towards woven logic from organic electronic fibres. Nat. Mater. 2007, 6, 357-362.

124. Hamedi, M.; Herlogsson, L.; Crispin, X.; Marcilla, R.; Berggren, M.; Inganäs, O. Fiber-embedded electrolyte-gated field-effect transistors for e-textiles. Adv. Mater. 2009, 21, 573-577.

125. Bonderover, E.; Wagner, S. A Woven Inverter Circuit for E-Textile Applications. IEEE Electron Device Lett. 2004, 25, 295-297.

126. Holonyak, N. News - First LED by the GE Engineer, Nick Holonyak. Available online: http://www.gelighting.com/LightingWeb/emea/news-and-media/news/First-LED-by-the-GEengineer-Nick-Holonyak.jsp (accessed on 16 July 2015).

127. Tan, J.J.; Zou, C.Q.; Du, S.H.; Tan, J.T. Simulation of MIMO channel characteristics for indoor visible light communication with LEDs. Opt. Int. J. Light Electron Opt. 2014, 125, 44-49.

128. Yu, H.; Deng, D.; Chen, L.; Chen, D.; Zhong, J.; Zhao, H.; Xu, S. Luminescent properties of novel $\mathrm{Ca}_{2.89} \mathrm{Mg}_{0.11}\left(\mathrm{PO}_{4}\right)_{2}: \mathrm{Eu}^{2+}$ single-phase white light-emitting phosphor for white LEDs. Ceram. Int. 2015, 41, 3800-3805.

129. Zhang, Z.; Wang, J.; Yin, Y.; Zhou, J.; Zhou, S.; Pan, Y. A novel green-to-yellow emitting phosphor: $\mathrm{BaSi}_{2} \mathrm{SN}_{2.67}: \mathrm{Eu}^{2+}$ for potential application in UV-LEDs. Opt. Mater. 2013, 35, 1273-1275.

130. Park, S.; Choi, I.-M.; Kim, S.-S.; Kim, S.-M. A portable mid-range localization system using infrared LEDs for visually impaired people. Infrared Phys. Technol. 2014, 67, 583-589.

131. Lourenço, M.A.; Homewood, K.P. Crystalline-silicon-based infra-red LEDs and routes to laser diodes. Thin Solid Films 2011, 519, 8441-8445.

132. Tang, C.W.; VanSlyke, S.A. Organic electroluminescent diodes. Appl. Phys. Lett. 1987, 51, 913-915.

133. Misra, A.; Kumar, P.; Kamalasanan, M.N.; Chandra, S. White organic LEDs and their recent advancements. Semicond. Sci. Technol. 2006, 21, R35-R47.

134. O’Connor, B.; An, K.H.; Zhao, Y.; Pipe, K.P.; Shtein, M. Fiber shaped light emitting device. Adv. Mater. 2007, 19, 3897-3900.

135. Yang, H.; Lightner, C.R.; Dong, L. Light-emitting coaxial nanofibers. ACS Nano 2012, 6, $622-628$. 
136. Wise, K.D. Integrated sensors: Interfacing electronics to a non-electronic world. Sens. Actuators 1981, 2, 229-237.

137. Nese, M.; Seeberg, B.E. Silicon MEMS pressure sensors for aerospace applications. ASME Proc. 2006, 195-198.

138. Lin, L.; Yun, W. MEMS Pressure Sensors for Aerospace Applications. In Proceedings of 1998 IEEE Aerospace Conference, Aspen, CO, USA, 28 March 1998; Volume 1, pp. 429-436.

139. Mishra, V.; Singh, N.; Tiwari, U.; Kapur, P. Fiber grating sensors in medicine: Current and emerging applications. Sens. Actuators Phys. 2011, 167, 279-290.

140. Girão, P.S.; Ramos, P.M.P.; Postolache, O.; Miguel Dias Pereira, J. Tactile sensors for robotic applications. Measurement 2013, 46, 1257-1271.

141. Wu, W.; Liang, L.; Xu, R.; Liu, X.; Qin, Z. The application of fiber grating sensor network in port-machinery monitoring. Opt. Lasers Eng. 2010, 48, 427-434.

142. Kinnunen, M.; Mian, S.Q.; Oinas-Kukkonen, H.; Riekki, J.; Jutila, M.; Ervasti, M.; Ahokangas, P.; Alasaarela, E. Wearable and mobile sensors connected to social media in human well-being applications. Telemat. Inform. 2016, 33, 92-101.

143. Mansoor, M.; Haneef, I.; Akhtar, S.; De Luca, A.; Udrea, F. Silicon diode temperature sensors-A review of applications. Sens. Actuators Phys. 2015, 232, 63-74.

144. Della Lucia, F.; Zambrozi, P., Jr.; Frazatto, F.; Piazzetta, M.; Gobbi, A. Design, fabrication and characterization of SAW pressure sensors for offshore oil and gas exploration. Sens. Actuators Phys. 2015, 222, 322-328.

145. Yamazoe, N.; Shimizu, Y. Humidity sensors: Principles and applications. Sens. Actuators 1986, 10, 379-398.

146. Zhu, Z.-T.; Mason, J.T.; Dieckmann, R.; Malliaras, G.G. Humidity sensors based on pentacene thin-film transistors. Appl. Phys. Lett. 2002, 81, 4643-4645.

147. Merkys, A.J.; Laurinavichius, R.S.; Rupainene, O.J.; Savichene, E.K.; Jaroshius, A.V.; Shvegzhdene, D.V.; Bendoraityte, D.P. The state of gravity sensors and peculiarities of plant growth during different gravitational loads. Adv. Space Res. 1983, 3, 211-219.

148. Pasterkamp, H.; Kraman, S.S.; DeFrain, P.D.; Wodicka, G.R. Measurement of respiratory acoustical signals. Comparison of sensors. Chest 1993, 104, 1518-1525.

149. Turner, R.C.; Fuierer, P.A.; Newnham, R.E.; Shrout, T.R. Materials for high temperature acoustic and vibration sensors: A review. Appl. Acoust. 1994, 41, 299-324.

150. Papadimitriou, C.; Fritzen, C.-P.; Kraemer, P.; Ntotsios, E. Fatigue predictions in entire body of metallic structures from a limited number of vibration sensors using Kalman filtering. Struct. Control Health Monit. 2011, 18, 554-573.

151. Inaba, M.; Hoshino, Y.; Nagasaka, K.; Ninomiya, T.; Kagami, S.; Inoue, H. A Full-Body Tactile Sensor Suit Using Electrically Conductive Fabric and Strings. In Proceedings of the 1996 IEEE/RSJ International Conference on Intelligent Robots and Systems '96 (IROS 96), Osaka, Japan, 4-8 November 1996; Volume 2, pp. 450-457.

152. Shimojo, M.; Namiki, A.; Ishikawa, M.; Makino, R.; Mabuchi, K. A tactile sensor sheet using pressure conductive rubber with electrical-wires stitched method. IEEE Sens. J. 2004, 4, 589-596.

153. Takamatsu, S.; Kobayashi, T.; Shibayama, N.; Miyake, K.; Itoh, T. Fabric pressure sensor array fabricated with die-coating and weaving techniques. Sens. Actuators Phys. 2012, 184, 57-63. 
154. Ma, R.; Lee, J.; Choi, D.; Moon, H.; Baik, S. Knitted fabrics made from highly conductive stretchable fibers. Nano Lett. 2014, 14, 1944-1951.

155. Starner, T. Human-powered wearable computing. IBM Syst. J. 1996, 35, 618-629.

156. Wang, X.; Song, J.; Liu, J.; Wang, Z.L. Direct-current nanogenerator driven by ultrasonic waves. Science 2007, 316, 102-105.

157. Paradiso, J.; Starner, T. Energy scavenging for mobile and wireless electronics. IEEE Pervasive Comput. 2005, 4, 18-27.

158. Zhang, M.; Gao, T.; Wang, J.; Liao, J.; Qiu, Y.; Yang, Q.; Xue, H.; Shi, Z.; Zhao, Y.; Xiong, Z.; Chen, L. A hybrid fibers based wearable fabric piezoelectric nanogenerator for energy harvesting application. Nano Energy 2015, 13, 298-305.

159. Bouendeu, E.; Greiner, A.; Smith, P.J.; Korvink, J.G. A low-cost electromagnetic generator for vibration energy harvesting. IEEE Sens. J. 2011, 11, 107-113.

160. Mitcheson, P.D.; Miao, P.; Stark, B.H.; Yeatman, E.M.; Holmes, A.S.; Green, T.C. MEMS electrostatic micropower generator for low frequency operation. Sens. Actuators Phys. 2004, 115, 523-529.

161. Qin, Y.; Wang, X.; Wang, Z.L. Microfibre-nanowire hybrid structure for energy scavenging. Nature 2008, 451, 809-813.

162. Jeong, C.K.; Lee, J.; Han, S.; Ryu, J.; Hwang, G.-T.; Park, D.Y.; Park, J.H.; Lee, S.S.; Byun, M.; Ko, S.H.; et al. A hyper-stretchable elastic-composite energy harvester. Adv. Mater. 2015, 27, 2866-2875.

163. Zhong, J.; Zhang, Y.; Zhong, Q.; Hu, Q.; Hu, B.; Wang, Z.L.; Zhou, J. Fiber-based generator for wearable electronics and mobile medication. ACS Nano 2014, 8, 6273-6280.

164. Jung, S.; Lee, J.; Hyeon, T.; Lee, M.; Kim, D.-H. Fabric-based integrated energy devices for wearable activity monitors. Adv. Mater. 2014, 26, 6329-6334.

165. Lee, S.; Ko, W.; Oh, Y.; Lee, J.; Baek, G.; Lee, Y.; Sohn, J.; Cha, S.; Kim, J.; Park, J.; et al. Triboelectric energy harvester based on wearable textile platforms employing various surface morphologies. Nano Energy 2015, 12, 410-418.

166. Fan, F.-R.; Tian, Z.-Q.; Lin Wang, Z. Flexible triboelectric generator. Nano Energy 2012, 1, 328-334.

167. Zhu, G.; Pan, C.; Guo, W.; Chen, C.-Y.; Zhou, Y.; Yu, R.; Wang, Z.L. Triboelectric-generator-driven pulse electrodeposition for micropatterning. Nano Lett. 2012, 12, 4960-4965.

168. Du, Y.; Cai, K.; Chen, S.; Wang, H.; Shen, S.Z.; Donelson, R.; Lin, T. Thermoelectric fabrics: Toward power generating clothing. Sci. Rep. 2015, 5, 6411-6416.

169. Kim, M.-K.; Kim, M.-S.; Lee, S.; Kim, C.; Kim, Y.-J. Wearable thermoelectric generator for harvesting human body heat energy. Smart Mater. Struct. 2014, 23, 105002-105008.

170. Liang, D.; Yang, H.; Finefrock, S.W.; Wu, Y. Flexible nanocrystal-coated glass fibers for high-performance thermoelectric energy harvesting. Nano Lett. 2012, 12, 2140-2145.

171. O'Regan, B.; Grätzel, M. A low-cost, high-efficiency solar cell based on dye-sensitized colloidal $\mathrm{TiO}_{2}$ films. Nature 1991, 353, 737-740.

172. Kippelen, B.; Brédas, J.-L. Organic photovoltaics. Energy Environ. Sci. 2009, 2, 251-261.

173. Liu, D.; Kelly, T.L. Perovskite solar cells with a planar heterojunction structure prepared using room-temperature solution processing techniques. Nat. Photonics 2013, 8, 133-138. 
174. Chen, S.-G.; Stradins, P.; Gregg, B.A. Doping highly ordered organic semiconductors: Experimental results and fits to a self-consistent model of excitonic processes, doping, and transport. J. Phys. Chem. B 2005, 109, 13451-13460.

175. Pan, S.; Yang, Z.; Chen, P.; Fang, X.; Guan, G.; Zhang, Z.; Deng, J.; Peng, H. Carbon nanostructured fibers as counter electrodes in wire-shaped dye-sensitized solar cells. J. Phys. Chem. C 2014, 118, 16419-16425.

176. Cai, X.; Hou, S.; Wu, H.; Lv, Z.; Fu, Y.; Wang, D.; Zhang, C.; Kafafy, H.; Chu, Z.; Zou, D. All-carbon electrode-based fiber-shaped dye-sensitized solar cells. Phys. Chem. Chem. Phys. 2012, 14, 125-130.

177. Hou, S.; Cai, X.; Fu, Y.; Lv, Z.; Wang, D.; Wu, H.; Zhang, C.; Chu, Z.; Zou, D. Transparent conductive oxide-less, flexible, and highly efficient dye-sensitized solar cells with commercialized carbon fiber as the counter electrode. J. Mater. Chem. 2011, 21, 13776-13779.

178. Cai, F.; Chen, T.; Peng, H. All carbon nanotube fiber electrode-based dye-sensitized photovoltaic wire. J. Mater. Chem. 2012, 22, 14856-14860.

179. Zhang, L.; Shi, E.; Li, Z.; Li, P.; Jia, Y.; Ji, C.; Wei, J.; Wang, K.; Zhu, H.; Wu, D.; et al. Wire-supported CdSe nanowire array photoelectrochemical solar cells. Phys. Chem. Chem. Phys. 2012, 14, 3583-3588.

180. Grätzel, M. The light and shade of perovskite solar cells. Nat. Mater. 2014, 13, 838-842.

181. McGehee, M.D. Perovskite solar cells: Continuing to soar. Nat. Mater. 2014, 13, 845-846.

182. Zhou, H.; Chen, Q.; Li, G.; Luo, S.; Song, T.-b.; Duan, H.-S.; Hong, Z.; You, J.; Liu, Y.; Yang, Y. Interface engineering of highly efficient perovskite solar cells. Science 2014, 345, 542-546.

183. Jeon, N.J.; Noh, J.H.; Yang, W.S.; Kim, Y.C.; Ryu, S.; Seo, J.; Seok, S.I. Compositional engineering of perovskite materials for high-performance solar cells. Nature 2015, 517, 476-480.

184. Qiu, L.; Deng, J.; Lu, X.; Yang, Z.; Peng, H. Integrating perovskite solar cells into a flexible fiber. Angew. Chem. Int. Ed. 2014, 53, 10425-10428.

185. Liu, J.; Mirri, F.; Notarianni, M.; Pasquali, M.; Motta, N. High performance all-carbon thin film supercapacitors. J. Power Sources 2014, 274, 823-830.

186. Wang, G.; Zhang, L.; Zhang, J. A review of electrode materials for electrochemical supercapacitors. Chem Soc Rev 2012, 41, 797-828.

187. Yu, Z.; Tetard, L.; Zhai, L.; Thomas, J. Supercapacitor electrode materials: Nanostructures from 0 to 3 dimensions. Energy Env. Sci 2015, 8, 702-730.

188. Yang, P.; Xiao, X.; Li, Y.; Ding, Y.; Qiang, P.; Tan, X.; Mai, W.; Lin, Z.; Wu, W.; Li, T.; et al. Hydrogenated $\mathrm{ZnO}$ core-shell nanocables for flexible supercapacitors and self-powered systems. ACS Nano 2013, 7, 2617-2626.

189. Jiang, H.; Yang, L.; Li, C.; Yan, C.; Lee, P.S.; Ma, J. High-rate electrochemical capacitors from highly graphitic carbon-tipped manganese oxide/mesoporous carbon/manganese oxide hybrid nanowires. Energy Environ. Sci. 2011, 4, 1813-1819.

190. Li, Q.; Wang, Z.-L.; Li, G.-R.; Guo, R.; Ding, L.-X.; Tong, Y.-X. Design and synthesis of $\mathrm{MnO}_{2} / \mathrm{Mn} / \mathrm{MnO}_{2}$ sandwich-structured nanotube arrays with high supercapacitive performance for electrochemical energy storage. Nano Lett. 2012, 12, 3803-3807. 
191. Zhang, Z.; Chen, X.; Chen, P.; Guan, G.; Qiu, L.; Lin, H.; Yang, Z.; Bai, W.; Luo, Y.; Peng, H. Integrated polymer solar cell and electrochemical supercapacitor in a flexible and stable fiber format. Adv. Mater. 2014, 26, 466-470.

192. Jiang, D.; Jin, Z.; Henderson, D.; Wu, J. Solvent effect on the pore-size dependence of an organic electrolyte supercapacitor. J. Phys. Chem. Lett. 2012, 3, 1727-1731.

193. Jost, K.; Perez, C.R.; McDonough, J.K.; Presser, V.; Heon, M.; Dion, G.; Gogotsi, Y. Carbon coated textiles for flexible energy storage. Energy Environ. Sci. 2011, 4, 5060-5067.

194. Pasta, M.; La Mantia, F.; Hu, L.; Deshazer, H.D.; Cui, Y. Aqueous supercapacitors on conductive cotton. Nano Res. 2010, 3, 452-458.

195. Prosini, P.P.; Pozio, A.; Botti, S.; Ciardi, R. Electrochemical studies of hydrogen evolution, storage and oxidation on carbon nanotube electrodes. J. Power Sources 2003, 118, 265-269.

196. Zou, D.; Lv, Z.; Cai, X.; Hou, S. Macro/microfiber-shaped electronic devices. Nano Energy 2012, 1, 273-281.

(C) 2015 by the authors; licensee MDPI, Basel, Switzerland. This article is an open access article distributed under the terms and conditions of the Creative Commons Attribution license (http://creativecommons.org/licenses/by/4.0/). 